University of Wollongong

Research Online

Faculty of Engineering and Information

Faculty of Engineering and Information

Sciences - Papers: Part B

Sciences

2017

Behaviour of fibre-reinforced RPC columns under different loading conditions

Muhammad N. S Hadi

University of Wollongong, mhadi@uow.edu.au

Ahmed Al-Tikrite

University of Wollongong, afs017@uowmail.edu.au

Follow this and additional works at: https://ro.uow.edu.au/eispapers1

Part of the Engineering Commons, and the Science and Technology Studies Commons

Research Online is the open access institutional repository for the University of Wollongong. For further information contact the UOW Library: research-pubs@uow.edu.au 


\title{
Behaviour of fibre-reinforced RPC columns under different loading conditions
}

\author{
Abstract \\ This paper investigates experimentally the influence of steel fibres inclusion on the behaviour of Reactive \\ Powder Concrete (RPC) columns. Micro steel fibre (MF) and deformed steel fibres (DF) were used. Steel \\ fibres were hybridized to produce hybrid steel fibre (HF). Sixteen RPC specimens were cast and tested \\ under axial loading, eccentric loading $(25 \mathrm{~mm}$ and $50 \mathrm{~mm})$ and four-point bending. Results of testing \\ demonstrated that RPC specimens that included MF exhibited 8-58\% higher load carrying capacity \\ compared to the reference NF specimens. Moreover, RPC specimens that included HF showed $29-408 \%$ \\ higher ductility under different loading conditions compared to the reference specimens (NF). Also, the \\ RPC specimens containing steel fibres exhibited 2-32\% higher axial deformation under different loading \\ conditions compared to NF specimens. Finally, it was observed that the RPC specimens reinforced with \\ HF showed delayed spalling of concrete cover more than the RPC specimens that included MF and DF.

\section{Disciplines} \\ Engineering | Science and Technology Studies

\section{Publication Details} \\ Hadi, M. N. S. \& Al-Tikrite, A. (2017). Behaviour of fibre-reinforced RPC columns under different loading \\ conditions. Construction and Building Materials, 156 293-306.
}




\title{
Behaviour of Fibre-Reinforced RPC Columns under Different Loading Conditions
}

\author{
Muhammad N. S. Hadi ${ }^{1}$
}

${ }^{1}$ Assoc. Professor, School of Civil, Mining and Environmental Engineering, University of Wollongong, Australia, Corresponding Author.

Email: mhadi@uow.edu.au

Ahmed Al-Tikrite ${ }^{2}$

${ }^{2} \mathrm{PhD}$ Candidate, Structural Engineering, School of Civil, Mining and Environmental Engineering, University of Wollongong, Australia. Email: afs017@uowmail.edu.au

\section{Abstract}

This paper investigates experimentally the influence of steel fibres inclusion on the behaviour of Reactive Powder Concrete (RPC) columns. Micro steel fibre (MF) and deformed steel fibres (DF) were used. Steel fibres were hybridized to produce hybrid steel fibre (HF). Sixteen RPC specimens were cast and tested under axial loading, eccentric loading (25 $\mathrm{mm}$ and 50 $\mathrm{mm}$ ) and four-point bending. Results of testing demonstrated that RPC specimens that included MF exhibited $8 \%-58 \%$ higher load carrying capacity compared to the reference NF specimens. Moreover, RPC specimens that included HF showed 29\%-408\% higher ductility under different loading conditions compared to the reference specimens (NF). Also, the RPC specimens containing steel fibres exhibited 2\%-32\% higher axial deformation under different loading conditions compared to NF specimens. Finally, it was observed that the RPC specimens reinforced with HF showed delayed spalling of concrete cover more than the RPC specimens that included MF and DF.

Keyword: RPC column; Micro steel fibre (MF); Deformed steel fibre (DF); Hybrid steel fibre (HF); Axial load; Flexural load; Ductility; Interaction diagram. 


\section{Introduction}

Reactive Powder Concrete (RPC) is a special type of ultra-high performance concrete characterised by its strength, durability and toughness. The excellent performance is attributed to the utilization of admixtures, very fine sand and low water/binder ratio in addition to the exclusion of the coarse aggregates. Also, RPC is considered as a promising construction material for civil engineering and military applications due to its superior properties. The first structure constructed from RPC in the world was Sherbrooke Bridge in Canada in 1997 [1-5]. In addition, utilization of RPC in structural applications such as in columns increases the design efficiency through decreasing the dimensions of the concrete elements and reducing the concrete volume of the entire structure. The RPC, however, is a very brittle material which requires more confinement than the normal strength concrete to achieve the ductility improvement which is limited by the design codes due to the possible congestion of reinforcement. Also, the sudden failure due to the excessive brittleness limits the wide spread utilization of RPC especially in seismic activity zones. Therefore, the inclusion of steel fibre is necessary to mitigate the brittleness and to increase the strength and toughness of RPC.

Hsu and Hsu [6], Mansur et al. [7] and Campione et al. [8] reported that the inclusion of steel fibres in the High-Strength Concrete (HSC) results in a significant increase in the strength of HSC. In addition, the fracture energy of the concrete was effectively improved after the addition of steel fibres to the concrete $[9,10]$. The action of steel fibre in concrete bridges the cracks that may result from lateral expansion of columns under compression and resists crack widening via pull-out of fibres from concrete. Moreover, the addition of steel fibres to concrete in columns delays the spalling phenomenon of the concrete cover and increases the ductility noticeably. Steel fibre content in the concrete plays a key role in strength and ductility. Hadi [11] explored the inclusion of steel fibres in the high strength concrete 
columns. Results of testing demonstrated that steel fibres content effectively increases the maximum load of the HSC columns and delays the cover spalling phenomena noticeably. Ikponmwosa and Salau [12] investigated the influence of short steel fibre inclusion on the behaviour of the normal strength concrete column. Results showed that increasing the volume fraction of steel fibre leads to an increase in the maximum column strength and the first crack load. Aoude et al [13] reported that the inclusion of steel fibres in the concrete columns markedly increased the peak axial load and improved the post peak behaviour of the column effectively. Moreover, Tokgoz et al. [14] reported that the incorporation of steel fibres in the high strength columns noticeably improves the confinement, deformability and the ductility of the column.

To maximize the enhancement due to the addition of steel fibres, past studies stated that the inclusion of different types of steel fibres can improve the performance of the concrete effectively. For instance, the inclusion of the microfiber of different diameters enhances the tensile behaviour of the concrete due to the influence of the fibres on the crack initiation and growth at different stages at failure $[15,16]$. Also, it is reported that the hybridization between steel fibres results in an increase in the strength and toughness of the concrete in comparison with the strength and the toughness of the concrete when one type of steel fibres was added [17]. This is attributed to the action of the steel fibres in controlling the formation of cracks which affects the tensile strength of the concrete. Several attempts were made to specify the interaction of hybridization of fibres to obtain the full advantage of steel fibre's action. For instance, it was reported that the ultimate compressive strain and the fracture energy was increased when a hybrid steel and polypropylene fibres were hybridized and added to the concrete [18-20]. Furthermore, Feldman and Zheng [21] stated that the hybridization of fibres such as steel fibres and polypropylene fibres increases the ultimate strength and toughness of 
concrete. Moreover, the hybridization of different types of fibres having different properties is more efficient due to different actions of each fibre. Banthia and Sappakittipakorn [22] concluded that the addition of crimped steel fibre of different diameters and sizes results in an improvement of the toughness of the hybrid fibre concrete in comparison with the toughness of the concrete when one type of concrete were used. Yao et al. [23] investigated the inclusion of steel fibres, polypropylene (PP) and carbon fibres in a hybrid form in the concrete. Yao et al. [23] concluded that the inclusion of two different types of steel fibres, especially steel fibres and carbon fibres, in the concrete considerably improved the strength and toughness of the concrete.

The inclusion of hybrid straight steel fibres in the Ultra-High Performance Concrete (UHPC) was investigated by Kang et al. [24]. Macro and short fibres of different tensile strengths 1100-2700 MPa and different lengths 12-19.5 mm were hybridized and added to UHPC. The hybridizations were in different ratios. It was concluded that the addition of hybrid fibres effectively improves the tensile behaviour of the UHPC. Park et al. [25] investigated the inclusion of the hybrid steel fibre in the UHPC. Macro, micro and twisted steel fibre were utilized in different ratios. The conclusion was that the geometry, the shape and the content of the steel fibre influence the tensile behaviour, strain hardening and the post-cracking strength of the concrete. Yu et al. [26] reported that the inclusion of hybrid steel fibres that included long and short steel fibre has increased the flexural and compressive strength of the UHPC markedly.

This paper presents experimentally the influence of steel fibres' inclusion in an individual form and in a hybrid form on the characteristics of RPC specimens. Two types of steel fibres having different properties were selected which are micro steel fibres (MF) and deformed 
steel fibres (DF). Hybridization (HF) between these two types of steel fibres was performed in this study by blending $50 \%$ of the optimum ratio of each steel fibre to be hybridized. Hybrid steel fibre (HF) was obtained from $2 \% \mathrm{MF}$ and $1 \%$ DF to form $3 \% \mathrm{HF}$. Four groups of specimens were cast and tested. Each group include four specimens tested under concentric loading, eccentric loading ( $25 \mathrm{~mm}$ and $50 \mathrm{~mm}$ ) and four-point bending.

\subsection{Research significance}

The utilization of RPC by itself in structural members is not well desired due to the lack of toughness and its brittle behaviour compared with the normal strength concrete. In addition, increasing the strength of the concrete utilized in structural members requires more confinement which may interfere with ACI design code (ACI 318-14) which limits the minimum spacing between the confining helix to $25 \mathrm{~mm}$ [27]. In addition, increasing the confinement by reducing the pitch of the helices results in early spalling of the concrete cover due to the formation of separation plane between the confined core and the surrounding concrete cover $[28,29]$. Therefore, enhancing the ductility behaviour of RPC is necessary in order to cope with the steel reinforcement design. Consequently, steel fibres are added to the RPC specimens in individual form and in hybrid form to investigate the contribution of steel fibres in improving the behaviour of the column and the influence of the steel fibres hybridization on the performance of RPC column. For this purpose, 16 specimens divided into four groups of four specimens according to the variation in steel fibres type were cast and tested under different loading conditions. The steel reinforcement for all specimens was kept the same for all specimens to investigate the influence of the steel fibres on the behaviour of RPC specimens. 


\subsection{Preliminary study}

An investigation was conducted to optimise the optimum ratio of steel fibres to be utilized in RPC that enhances the performance of RPC in regards the strength and ductility under compression. Different ratios were utilized of the micro steel fibre (MF) and deformed steel fibre (DF). Results of testing demonstrated that the addition of $4 \% \mathrm{MF}$ and $2 \% \mathrm{DF}$ individually has improved the mechanical properties of the RPC. Moreover, the hybridization between $50 \%$ of the optimum ratio of MF (4\%) and $50 \%$ of the optimum ratio of DF (2\%) which forms $3 \% \mathrm{HF}(2 \% \mathrm{MF}$ and $1 \% \mathrm{DF})$ resulted in enhanced behaviour of RPC under compression.

\section{Experimental Program}

\subsection{Specimen Design and Preparation}

In order to investigate the influence of each steel fibre on the behaviour of the RPC specimens under different loading conditions, 16 specimens of $200 \mathrm{~mm}$ in diameter and $800 \mathrm{~mm}$ in length were cast. Twelve specimens were tested under concentric and eccentric loadings and four specimens were tested as beam under four-point bending. All specimens were reinforced longitudinally with six deformed steel bars of $12 \mathrm{~mm}$ diameter (6N12). Smooth steel bar of a $10 \mathrm{~mm}$ diameter was used as helix (R10). The pitch of the helices was $40 \mathrm{~mm}$. The details of the designed specimens are presented in Table 1.

To explore the influence of the steel fibre's addition on the behaviour of RPC specimens, four groups of four specimens were made. The first group of specimens were non-fibrous RPC (NF) and acted as a reference. The second group of four specimens included micro steel fibre (MF) in the RPC at $4 \%$ of the total volume. The third group of four specimens included deformed steel fibre (DF) at $2 \%$ of the total volume. The forth group included the hybrid steel 
fibre (HF) at $3 \%(2 \% \mathrm{MF}$ and $1 \% \mathrm{DF})$. To identify the type of specimen and the loading condition, the specimens were labelled by series of letters representing the presence of steel fibres and loading conditions. The first two letters represent the presence of steel fibres. The letter after the hyphen represents the loading condition of the specimen. The concentric and eccentric loadings were represented by one letter and different numbers depending on the eccentricity. For concentric loading, the number was " 0 " while for $25 \mathrm{~mm}$ and $50 \mathrm{~mm}$ eccentricity the number was 25 and 50, respectively. The four-point bending was represented by the letters 'PB". For example, the non-fibrous RPC specimen (reference) tested under concentric loading was labelled as NF-E0. The RPC specimen that included hybrid steel fibres tested under four-point bending was labelled as HF-PB.

\subsection{Materials}

The materials used in all mixes are as follows: general-purpose Portland cement at $955 \mathrm{~kg} / \mathrm{m}^{3}$. The silica fume utilized was amorphous high-grade densified silica fume powder at 229 $\mathrm{kg} / \mathrm{m}^{3}$. The sand utilized was local natural sand sieved to a size less than $600 \mu \mathrm{m}$ and the specific gravity was 2.65 . The amount of the sand utilized was $974 \mathrm{~kg} / \mathrm{m}^{3}$. Silica flour $200 \mathrm{G}$ was utilized in the mixture at $10 \mathrm{~kg} / \mathrm{m}^{3}$. Water reducer and retarder (superplasticizer) was utilized at $52.6 \mathrm{~L} / \mathrm{m}^{3}$. The water/binder ratio was 0.133 . Two types of steel fibres were used in this study: micro steel fibres and deformed steel fibres (see Fig.1). The micro steel fibre (MF) utilized in this study was $0.2 \mathrm{~mm}$ in diameter and $6 \mathrm{~mm}$ in length. The nominal tensile strength of MF was $2900 \mathrm{MPa}$ [30]. The deformed steel fibre utilized was $0.55 \mathrm{~mm}$ in diameter, $18 \mathrm{~mm}$ in length and had $800 \mathrm{MPa}$ nominal tensile strength [31]. Table 2 shows the characteristics of the steel fibre. The RPC mixture utilized was based on a mixture proposed by Richard and Cheyrezy [5]. Some modifications were made to keep the mixture within the acceptable flowability limits. 
177 Plastic tube moulds were used as a formwork for casting the RPC specimens. The inner

\subsection{Specimen Fabrication and Instrumentation} diameter of the plastic tubes was $200 \mathrm{~mm}$ and the length was $800 \mathrm{~mm}$. A wooden formwork was built to hold the plastic tube vertically. Then, the longitudinal steel reinforcement N12 was cut to a length of $760 \mathrm{~mm}$. The concrete cover was $20 \mathrm{~mm}$ from the sides, top and bottom. The helix which was smooth steel bar R10 was coiled. The core diameter of the helix was $150 \mathrm{~mm}$ centre to centre and the pitch was $40 \mathrm{~mm}$. Fig. 2 shows the specimen dimensions and reinforcement details.

The steel reinforcement cage was prepared by fixing the helix to a steel base. Two spacers were used: vertical spacers to ensure the spacing between the helices was $40 \mathrm{~mm}$ and horizontal spacers to maintain the spaces between all the longitudinal steel bars were equal. After finishing the steel reinforcement cage, the steel reinforcement cages were placed in the plastic tube moulds. Fig. 3 shows the fabrication of the tested specimens.

The flowable RPC was poured in three stages to ensure that no voids or air bubbles were entrapped in the concrete mixture. After casting the specimens, the curing was done by covering the specimens by a wet hessian fabric and plastic sheets to keep the moisture conditions of the specimens. The curing period continued for 28 days until the testing day of the specimens.

To record the applied load and the deformation while testing, two Linear Variable Differential Transformers (LVDTs) in addition to the LVDT of the testing machine were used. Moreover, a laser triangulation was used when testing the specimens under eccentricity and pure bending 
to capture the lateral deformation and the midspan deflection. Fig. 4 shows the compression testing machine supplied with LVDTs during concentric loading test.

\subsection{Testing Equipment and Procedure}

The specimens were tested either under concentric, eccentric and four-point bending. A compression testing machine of a capacity of $5000 \mathrm{kN}$ was used. For the specimens tested under axial loads, before starting the test, both ends of the specimens were capped by highstrength plaster to get a uniform and levelled surface at both ends. As well as, both ends of the specimens were wrapped with a single layer of $100 \mathrm{~mm}$ wide CFRP to prevent the premature failure of concrete during the axial loading test. Two circular loading heads of $250 \mathrm{~mm}$ diameter were used at both ends. The loading heads contain three grooves, one for the concentric and two for the eccentric loading at different eccentricities $(25 \mathrm{~mm}$ and $50 \mathrm{~mm})$. Two plates with overhang edge were used as surface loading adjustment which fit the grooves at the loading heads and touches the machine plates to transfer the load from the machine to the specimens based on the conditions of loading (see Fig. 4 b). For the specimens tested under four-point bending, two rings were placed at the top and the bottom of the specimen. The length of the span of the beam specimen was $700 \mathrm{~mm}$. The distance from the support to the loading point was $233.3 \mathrm{~mm}$. The specimens were divided into three equal lengths of $233.3 \mathrm{~mm}$. Fig. 5 shows the RPC Specimens tested under four-point bending.

The test was started by loading the specimen with a displacement controlled loading rate of $(0.005 \mathrm{~mm} / \mathrm{s})$ until failure. The data that were measured by the LVDTs and the laser triangulation were stored in a data logger which was connected to them and recorded the data every 2 seconds. 


\section{Experimental Results and Analysis}

\subsection{Failure modes of the tested specimens}

The tests of all specimens were continued until failure. The pattern of failure was controlled by the loading conditions and the presence of steel fibre. For concentric loading, the reference Specimen NF-E0 failed by the buckling of the longitudinal steel bars and spalling of the concrete cover at the maximum load. Then the load was resisted by the concrete core confined by the transverse steel reinforcement until the rupture of the helix. Fig. 6 shows the buckling of the longitudinal steel reinforcement after failure of Specimen NF-E0. The addition of steel fibres to the RPC influenced the scenario of spalling of concrete cover. The first yielding failure for specimens with steel fibres was increased and the increment in the maximum load was proportional to the steel fibres content and geometry. The higher the amount of steel fibre, the higher was the maximum load at failure. Furthermore, the addition of steel fibre resulted in the concrete cover not to spall off after the maximum load failure despite the cracks that appeared on the surface. The concrete cover spalled off at the fracture of the helix. Nevertheless, the failure of fibrous concrete specimens also occurred by the buckling of the longitudinal reinforcement after the concrete reached the maximum load. The failure modes of the tested specimens are shown in Fig. 7 and Fig. 8.

For specimens tested under eccentricity and four-point bending, the failure started when the yield load was reached. Longitudinal hair line cracks started to appear at the compression face and transverse hairline cracks started to appear in the tension face. After the maximum axial load was reached, the concrete cover at the mid height of the specimen in the compression face started to crush while the transverse cracks in the tension face started to widen until the steel reinforcement appeared at specimens' failure. It was observed that the 
failure of Specimens NF-E25 and MF-E25 occurred at the lower third of the specimens. This might be due to the rupture of the transverse steel reinforcement at the compression zone.

For specimens tested under four-point bending, the failure was similar to the failure that occurred when the specimens were tested under eccentric loading. The failure started in the compression face with transverse cracks appearing in the tension face of the specimens. The steel reinforcement, however, has withstood the applied load until the rupture of the helix. It was noticed that the longitudinal steel bar in the tension zone was thinned to a lower diameter due to the bending load that was resisted by the steel bars after the concrete cracked and the steel bars resisted the crack widening until failure (see Fig. 9).

\subsection{Ductility of the tested specimens}

Ductility of concrete is defined as the ability of concrete to deform elastically without experiencing failure. The ductility of the RPC specimens was calculated by dividing the area under the load-deformation curve into two areas [32-36]. The ductility $\lambda$ can be found:

$$
\lambda={ }^{A_{2}} / A_{1}
$$

where, $A_{1}$ is the area under the load-deformation curve from zero to $\delta_{\mathrm{y}}$ (Fig. 10) and $A_{2}$ is the area under load-deformation curve from zero to $\delta_{\mathrm{u}}$ (Fig. 10). The ultimate axial load was assumed to be at $85 \%$ of the maximum axial load based on Pessiki and Pieroni [29] definition. The yield load can found by drawing two lines, the tangent which is the best regression fit line that touches the elastic branch of the ascending load-deformation curve is the first line. The second line is a horizontal line corresponding to the maximum axial load. The deformation corresponding to the intersection of the two lines is $\delta_{\mathrm{y}}$ [37] as shown in Fig. 10. 
The specimens that included HF exhibited the highest ductility compared with the other specimens. The ductility of Specimens HF-E0, HF-E25, HF-E50 and HF-PB was increased in comparison with the corresponding reference specimens by $76 \%, 29 \%, 47 \%$ and $408 \%$, respectively. This might be attributed to the interaction of the short steel fibres in bridging the micro cracks and preventing the propagation of the micro cracks while the long steel fibres prevented widening of cracks [38].

The increase in the ductility of Specimens MF-E0, MF-E25, MF-E50 and MF-PB compared with the corresponding reference specimens was $16 \%, 21 \%, 41 \%$ and $310 \%$, respectively. The increase in the ductility of specimens that included MF ranks the second after the specimens that included HF. This is due to the ability of the micro steel fibres to bridge the micro cracks effectively and inhibit the initiation and the propagation of the micro cracks. However, the role of the micro steel fibre ends after the applied load become higher than the bonding strength between the concrete and the micro steel fibres which results in debonding of the micro steel fibres with concrete.

The lowest increase in the ductility in comparison with the corresponding reference specimens was achieved by DF specimens. The increase in the ductility of Specimens DF-E0, DF-E25, DF-E50 and DF-PB was 2\%, 2\%, 4\% and 246\%, respectively, compared with the corresponding reference specimens. The slight increase in the ductility of specimens that included DF compared to the ductility of the specimens that included HF and MF might be due to the slippage of the deformed steel fibre that holds the macro cracks till the stress applied on the crack become higher than the bonding between DF and the concrete which causes slippage of steel fibres [39]. 


\subsection{Behaviour of RPC specimens under concentric load}

Four RPC specimens were tested under concentric axial load. One specimen was non-fibrous RPC and acted as the reference Specimen NF-E0 while the other three RPC specimens have included MF, DF and HF and labelled as MF-E0, DF-E0 and HF-E0. Table 3 presents the results of the tested specimens under concentric loading. It was observed that Specimen NFE0 has failed in a brittle manner with a smashing sound after reaching the maximum axial load. Conversely, Specimens MF-E0, DF-E0, and HF-E0 failed after reaching the maximum axial load with low cracking sound. All of the specimens failed by buckling of the longitudinal steel reinforcement and rupture of the helix. The ascending branch of the load deformation curve of the tested specimens differs in slope due to the variation in the modulus of elasticity of the RPC. It was noticed that the presence of fibres in RPC columns delayed the early cover spalling of the column specimens through keeping the concrete cover connected to the core at high loads. This action of steel fibres led to the concrete cover contributing with the concrete core in sustaining the applied load at the peak load and post peak load until the debonding of steel fibres from the concrete. As such, an increase in the load carrying capacity of the RPC specimens was noticed compared to the plain RPC which has experienced early cover spalling before reaching the peak axial load. So, the maximum axial load sustained by the specimens that included steel fibres was higher than that of the non-fibrous specimen (the reference). The addition of steel fibres obviously increased the maximum axial load of Specimens MF-E0, DF-E0 and HF-E0 by $32 \%, 9 \%$ and $23 \%$, respectively, compared to Specimen NF-E0. Similar findings were reported by Aoude et al. [13] and Hadi [40].

Type of steel fibre and geometry, however, influence the action of steel fibres in controlling the early cover spalling of column specimens. It was noticed that the RPC specimens that included micro steel fibres (MF) has sustained higher loads compared with its counterparts. 
The increase in the maximum axial load of Specimen MF-E0 is higher than the increase in the maximum axial load of Specimens DF-E0 and HF-E0. This could be attributed to the uniform distribution of MF in the whole body of the specimen without entangling between steel fibres which kept the concrete cover intact to the concrete core of specimens at high loads in addition to the fact of the ability of MF to inhibit the initiation and propagation of the micro cracks developed due to the applied load. As such, the early cover spalling of MF specimens was effectively delayed more than other specimens under loading. Hence, an increase in the sustained load was noticed for MF specimens and the other types of steel fibres specimens compared to the reference specimens.

The descending branch of the load-deformation curve is different in steep for different specimens. The descending branch of the load deformation curve of Specimen NF-E0 was dropped suddenly after reaching the maximum axial load by $22 \%$ from $3304 \mathrm{kN}$ to $2564 \mathrm{kN}$ at a deformation of $4.6 \mathrm{~mm}$. This sudden drop in strength occurred due to the spalling of the concrete cover after reaching the maximum axial load as well as due to the brittle behaviour of the RPC which failed suddenly without prior notice. Afterwards, the confined core started to sustain the applied load until failure. The failure of Specimen NF-E0 occurred at an axial deformation of $21.5 \mathrm{~mm}$ that correspond to an axial load of $1633 \mathrm{kN}$ by the fracture of the helix.

For Specimens MF-E0, DF-E0 and HF-E0, the degradation in the load carrying capacity started after reaching the maximum axial load of $4373 \mathrm{kN}, 3607 \mathrm{kN}$ and $4055 \mathrm{kN}$, respectively. However, the addition of steel fibres prevented the sudden drop of the descending branch of the axial load-deformation curve and delayed the spalling of concrete cover after reaching the maximum load. The post peak behaviour of the fibrous specimens 
was improved via softening action of the descending branch of the load-deformation curve after the maximum axial load was reached. Nevertheless, the influence of the steel fibres on the post peak behaviour is different depending on the geometry, content and type of steel fibres. The descending branch of the load-deformation curve was softer for Specimen HF-E0 than Specimens MF-E0 and DF-E0. Specimen HF-E0 has sustained the applied load after reaching the maximum axial load up to an axial deformation of $7.7 \mathrm{~mm}$ at an axial load of $2905 \mathrm{kN}$. This is due to the hybrid action of steel fibres resulted from the combined action of MF in resisting the initiation and propagation of the micro cracks and DF in restraining the macro cracks to be widened.

Specimens MF-E0 and DF-E0 have sustained the applied load after reaching the maximum axial load up to an axial deformation of $6.5 \mathrm{~mm}$ and 6.3, respectively, at an axial load of 3483 $\mathrm{kN}$ and $2668 \mathrm{kN}$, respectively. The lowest benefits of delaying the early spalling of concrete cover was obtained by the deformed steel fibres (DF) and the descending branch of the axial load-axial deformation curve of Specimen DF-E0 was steeper than that for Specimens MF-E0 and HF-E0. This is due to the slippage of DF from the matrix as the DF bridges the macro cracks which experience sudden widening after getting to the maximum axial load that DF could not hold and slips from the matrix [44]. Specimen DF-E0 failed at an axial deformation of $22.4 \mathrm{~mm}$ that corresponds to an axial load of $1791 \mathrm{kN}$. Specimen MF-E0 failed at an axial deformation of $21.7 \mathrm{~mm}$ that corresponds to an axial load of $1900 \mathrm{kN}$ when the helix had fractured. Specimens HF-E0 failed at an axial deformation of $28.4 \mathrm{~mm}$ that corresponds to an axial load of $1883 \mathrm{kN}$. Fig. 11 shows the axial load-deformation curves of the tested specimens under concentric loading. 


\subsection{Behaviour of RPC specimens under eccentric axial load}

Eight specimens were tested under eccentric axial loading. Four specimens tested under 25 mm eccentricity were marked as NF-E25, MF-E25, DF-E25 and HF-E25. Another four specimens tested under $50 \mathrm{~mm}$ eccentricity were marked as NF-E50, MF-E50, DF-E50 and HF-E50. Specimens NF-E25 and NF-E50 acted as the reference specimen in both groups of specimens. Tests results are presented in Table 4. It is obvious that the inclusion of the steel fibres enhanced the behaviour of the RPC specimens effectively compared with the corresponding reference specimens. The ascending branch of the load-deformation curve of the specimens tested under $25 \mathrm{~mm}$ eccentricity was influenced by the presence of steel fibres noticeably. The maximum axial load of the fibrous specimens was also influenced by the presence of steel fibres. The maximum axial load sustained by Specimen NF-E25 was 2194 $\mathrm{kN}$ and the ductility was 1.10 . However, the inclusion of steel fibres has delayed the early spalling of the concrete cover at latter stages of loading and kept the concrete cover to contribute with the concrete core in sustaining the applied load. Specifically, the inclusion of MF in the RPC specimens effectively delayed the early spalling of the concrete cover and achieved a maximum axial load of $2835 \mathrm{kN}$ for Specimen MF-E25 which is $29 \%$ higher than the maximum axial load sustained by Specimen NF-E25. The ductility of Specimen MF-E25 was 1.34 . The maximum axial load sustained by Specimen DF-E25 was $2246 \mathrm{kN}$ which is $2 \%$ higher than the maximum axial load of Specimen NF-E25. The ductility of Specimen DF-E25 was 1.12. The addition of HF to the RPC specimen increased the maximum axial load of Specimen HF-E25 compared to Specimen NF-E25 by 14\% and achieved a maximum axial load of $2511 \mathrm{kN}$. The ductility of Specimen HF-E25 is 1.42 which is $29 \%$ higher than that for Specimen NF-E25. The increase in the maximum axial load that the specimens sustained is an indication to the role of steel fibre in delaying the spall off phenomena of the concrete cover after reaching the maximum load as a result of inhibition of cracks' initiation and 
propagation. In addition, the steel fibres included in the core have added more confinement to the specimens in addition to the steel reinforcement confinement through the increase in the ductility of the fibrous specimens and the increase in the failure load and the corresponding deformation. Hadi [40] has found that the inclusion of steel fibres in concrete column results in an increase in the maximum load sustained under eccentric loading compared with the nonfibrous column.

When comparing with the concentrically loaded specimens, the maximum axial load sustained by Specimen NF-E0 which was $3304 \mathrm{kN}$ was decreased by $34 \%$ to $2194 \mathrm{kN}$ when $25 \mathrm{~mm}$ eccentricity was applied. The addition of MF, DF and HF mitigated the reduction in the sustained maximum loads when the eccentricity was applied. The maximum axial loads sustained by Specimens MF-E0, DF-E0 and HF-E0 were 4373 kN, 3607 kN and 4055 kN, respectively, were simply decreased by $14 \%, 32 \%$ and $24 \%$, respectively, when $25 \mathrm{~mm}$ eccentricity was applied in comparison with the decrease in the corresponding reference specimen. The maximum axial loads were decreased to $2835 \mathrm{kN}$ for Specimen MF-E25, 2246 kN for Specimen DF-E25 and 2511kN for Specimen HF-E25.

Applying $50 \mathrm{~mm}$ eccentricity had an impact on the load carrying capacity of the RPC specimens. The maximum axial load of Specimen NF-E50 was $1327 \mathrm{kN}$ and the ductility was 1.06. The inclusion of MF in the RPC specimen increased the maximum axial load of Specimen MF-E50 compared to Specimen NF-E50 by $29 \%$ to achieve $1711 \mathrm{kN}$. The ductility of Specimen MF-E50 was 1.49 which is $41 \%$ higher than the ductility of the corresponding reference specimen. The maximum axial load achieved by Specimen DF-E50 was $1414 \mathrm{kN}$ which represents an increase in the maximum axial load by $7 \%$ in comparison with Specimen NF-E50. The ductility of Specimen DF-E50 was 1.10 which is $4 \%$ higher than the ductility of 
Specimen NF-E50. The inclusion of HF in the RPC specimen has increased the maximum axial load of Specimen HF-E50 by 15\% compared to Specimen NF-E50 and achieved a maximum axial load of $1528 \mathrm{kN}$. The ductility that was achieved by Specimen HF-E50 was 1.56 which is $47 \%$ higher than the ductility of Specimen NF-E50. Table 4 presents the maximum axial load, corresponding deformation and the ductility of the RPC specimens tested under $25 \mathrm{~mm}$ and $50 \mathrm{~mm}$ eccentricity. Fig. 12 shows the axial eccentric load versus the axial and lateral deformation of the tested specimens at $25 \mathrm{~mm}$ and $50 \mathrm{~mm}$ eccentricity.

\subsection{Behaviour of RPC specimens under four-point bending}

Four specimens were tested under four-point bending. The non-fibrous RPC specimen marked as NF-PB acted as the reference specimen. The fibrous RPC specimens were marked as MFPB, DF-PB and HF-PB which have incorporated MF, DF and HF, respectively. Results of testing are presented in Table 5. It is worth to mention that to induce the deflection at midspan and to prevent the shear failure that might occur due to the short shear span to depth ratio, two layers of CFRP were wrapped along the shear span of Specimen NF-PB. Furthermore, to obtain the same comparison with the reference Specimen NF-PB, Specimens MF-PB, DF-PB and HF-PB were wrapped with CFRP along the shear span of the specimens.

It was noticed that all of the specimens have a linear ascending branch of the flexural loadmidspan deflection curve. The inclusion of the steel fibre effectively increased the maximum load sustained by the specimens under four-point bending generally. The maximum bending load sustained by the reference Specimen NF-PB was $356 \mathrm{kN}$ and the ductility obtained was 2.0. The inclusion of MF in the RPC specimen has strengthened the tension face of the specimens by inhibiting the initiation and propagation of the potential cracks which resulted in an increase in the maximum bending load sustained by Specimen MF-PB by about $10 \%$ 
compared to Specimen NF-PB and achieved $393 \mathrm{kN}$. The ductility achieved by Specimen MF-PB was 8.3 which is $310 \%$ higher than the ductility of Specimen NF-PB. The inclusion of DF and HF in the RPC specimens increased the maximum bending load sustained by Specimens DF-PB and HF-PB by $6 \%$ and $9 \%$, respectively, to achieve a maximum bending load of $379 \mathrm{kN}$ and $389 \mathrm{kN}$, respectively. The ductility achieved by Specimen DF-PB was 7.0 while the highest ductility obtained under four-point bending was 10.3 for Specimen HF-PB which is $408 \%$ higher than the ductility of Specimen NF-PB. This due to the interaction between the micro steel fibres in preventing the initiation and propagation of the micro cracks while deformed steel fibres bridging the macro cracks to prevent cracks widening. Fig. 13 shows the flexural load-midspan deflection curve of the tested specimens under four-point bending.

\section{Experimental axial load-bending moment interaction diagram}

An experimental axial load-bending moment interaction diagram was performed for concrete structural members subjected to concentric, eccentric and flexural loading. The axial loadbending moment interaction diagram includes the maximum axial loads and the maximum bending moments corresponding to the maximum loads obtained from the concentric loading, eccentric loading at $25 \mathrm{~mm}$, eccentric loading at $50 \mathrm{~mm}$ and four-point bending. For the concentric loading, the maximum axial load of Specimens NF-E0, MF-E0, DF-E0 and HF-E0 was used to be the first point at the axial-bending moment interaction diagram. The eccentric loading at $25 \mathrm{~mm}$ and $50 \mathrm{~mm}$ are representing the second and the third points at the axial load-bending moment interaction diagram. For the $25 \mathrm{~mm}$ and $50 \mathrm{~mm}$ eccentric loading, the following equation was used to calculate the moment at the maximum axial load:

$$
M=P_{\max }\left(e+\delta_{\max }\right)
$$


where, $P_{\max }$ is the maximum axial load, $e$ is the load eccentricity and $\delta_{\max }$ is the maximum lateral deformation that corresponds to the maximum axial deformation. For the specimens tested under four-point bending, the following equation was used to calculate the maximum moment at the maximum load:

$$
M=P_{\max } \times L / 6
$$

where, $P_{\max }$ is the max load, $L$ is span length of the flexural test arrangements. Table 6 presents the maximum load and the corresponding moment of the tested specimens. It is obvious that the addition of steel fibres to the RPC specimens effectively enhanced the maximum axial load and the corresponding bending moment of the tested specimens. This is due to the action of steel fibres in bridging of cracks resulted from the applied load. However, the improvement in the maximum axial load and the corresponding moment of the RPC specimens is different depending on the type and geometry of the steel fibres included. For instance, RPC specimens that incorporated MF gained higher maximum axial load than the RPC specimens that incorporated DF and HF. This is due to the influence of the micro steel fibres (MF) on the strength more than the long steel fibres which might be attributed to the well distribution of the micro steel fibres throughout the whole matrix without entangle likewise the long steel fibres. The RPC specimens that included HF influenced the post peak behaviour more than the maximum load due to the combination of MF and DF. As such, the maximum axial and bending loads and the corresponding moments were lower than these for the RPC specimens that included MF. Fig. 14 shows the experimental axial-bending moment interaction diagram of the tested specimens under concentric loading, eccentric loading (25 $\mathrm{mm}$ and $50 \mathrm{~mm}$ ) and four-point bending. 


\section{Conclusion}

498 The influence of steel fibre type, geometry and content on the behaviour of RPC column regarding load carrying capacity, ductility and mode failure in addition to the impact on the axial and lateral deformation was investigated. In this study, 16 specimens were tested under

501 concentric, eccentric and four-point bending. Based on the outcomes, the following 502 conclusion could be drawn:

1. The addition of the steel fibres positively influenced the behaviour of specimens and load carrying capacity of the RPC specimens under loading. In particular, the addition of the micro steel fibre (MF) had a considerable influence on the maximum load that sustained by specimens under different loading conditions. The maximum load sustained by Specimens MF-E0, MF-E25, MF-E50 and MF-PB was increased by 32\%, 29\%, 29\% and $10 \%$ in comparison with the maximum load sustained by the reference specimens under concentric, $25 \mathrm{~mm}$ eccentric loading, $50 \mathrm{~mm}$ eccentric loading and four-point bending, respectively.

2. The addition of steel fibres increased the ductility of the RPC specimens. The higher increases were obtained at the addition of the hybrid steel fibre (HF). The ductility of the Specimens HF-E0, HF-E25, HF-E50 and HF-PB was increased by 76\%, 29\%, 47\% and $408 \%$ compared to the ductility of the reference specimens under concentric, $25 \mathrm{~mm}$ eccentric loading, $50 \mathrm{~mm}$ eccentric loading and four-point bending, respectively.

3. The failure mode of RPC specimens was influenced by the addition of the steel fibres. The reference specimens had witnessed spalling of the concrete cover at the maximum axial load. However, the incorporation of steel fibres delayed the spalling of concrete cover after reaching the maximum axial load. The concrete cover remained integrated and has not exhibited full detachment from the core of concrete specimen until failure. 
4. The ultimate axial deformation corresponding to $85 \%$ of the maximum axial load of RPC specimens tested under concentric loading, eccentric loading and four-point bending was positively influenced by the addition of steel fibres. In particular, the higher increases in the ultimate axial deformation were obtained at the addition of HF steel fibres noticeably. The ultimate axial deformation of HF-E0, HF-E25and HF-50 and HF-PB was higher than the reference specimens by 54\%, 32\%, 57\% and 394\% under concentric loading, $25 \mathrm{~mm}$ eccentric loading, $50 \mathrm{~mm}$ eccentric loading and four-point bending, respectively.

Finally, the hybridization between MF and DF resulted in better ductility compared to MF and DF specimens individually. Also, the quantity of fibres was reduced by $1 \%$ compared to MF steel fibre with enhancement in the post peak behaviour of RPC specimens. Therefore, the utilization of HF steel fibres in RPC columns is economically and mechanically preferable.

\section{Acknowledgement}

The authors would like to thank the technical officers in High Bay Laboratories of the University of Wollongong, Australia for their support in performing the experimental work. Big thanks to Fibercon Company Australia for providing the deformed steel fibres. Also, the second author would like to acknowledge the Iraqi Government and the University of Wollongong, Australia for providing him with full support for his $\mathrm{PhD}$ scholarship.

\section{References}

1 Aitcin, P., Concrete the most widely used construction materials. ACI Special Publication, 1995. 154: 257-266. 
5452 Li, C.V. and Chan, Y. W., Determination of interfacial debond mode for fiber546 reinforced cementitious composites. Journal of Engineering Mechanics, 1994. 120(4): $547 \quad 707-719$.

5483 Collepardi, S., Coppola, L., Troli, R., and Collepardi, M., Mechanical properties of 549 modified reactive powder concrete. ACI Special Publications, 1997. 173: 1-22.

5504 Matte, V. and Moranville, M., Durability of reactive powder composites: influence of 551 silica fume on the leaching properties of very low water/binder pastes. Cement and $552 \quad$ Concrete Composites, 1999. 21(1): 1-9.

5535 Richard, P. and Cheyrezy, M.H., Reactive powder concretes with high ductility and 554 200-800 MPa compressive strength. ACI special Publication, 1994. 144: 507-518.

5556 Hsu, L.S., and Hsu, C.T.T., Stress-strain behaviour of steel-fibre high-strength concrete 556 under compression. ACI Structures Journal, 1994. 91(4): 448-457.

5577 Mansur, M.A., Chin, M.S., and Wee, T.H., Stress-strain relationship of confined high558 strength plain and fibre concrete. Journal of Materials in Civil Engineering, 1997. 9(4): $559 \quad 171-179$.

5608 Campione, G., Mindess, S., and Zingone, G., Compressive stress-strain behaviour of 561 normal and high strength carbon-fibre concrete reinforced with steel spirals, ACI $562 \quad$ Materials Journal, 1999. 96(1): 27-37.

5639 Kim, W.J., Kwak, M.S. and Lee, J.C., Fracture properties of high-strength steel fibre 564 concrete. In Proceedings of the Korea Concrete Institute Conference. Korea Concrete $565 \quad$ Institute, 2010.

56610 ACI Committee 544, State-of-the-Art Report on Fibre Reinforced Concrete. ACI 567 publication, American Concrete Institute, 1996.

56811 Hadi, M.N.S., Reinforcing Concrete Columns with Steel Fibres. Asian Journal of Civil 569 Engineering (Building and Housing), 2009. 10(1): 79-95. 
57012 Ikponmwosa, E.E. and Salau, M.A., Effect of Short Steel Fibre Reinforcement on 571 Laterized Concrete Columns. Journal of Sustainable Development, 2011. 4(1): 230.

57213 Aoude, H., Cook, W.D. and Mitchell, D., Behaviour of columns constructed with fibres 573 and self-consolidating concrete. ACI Structural Journal, 2009. 106(3): 349.

57414 Tokgoz, S., Dundar, C. and Tanrikulu, A.K., Experimental behaviour of steel fibre high 575 strength reinforced concrete and composite columns. Journal of Constructional Steel $576 \quad$ Research, 2012. 74:98-107.

57715 Lawler, J.S., Wilhelm, T. and Zampini, D., Shah, SP., Fracture processes of hybrid 578 fiber-reinforced mortar. Materials and Structures, 2003. 36(3): 197-208.

57916 Lawler, J. S., Zampini, D. and Shah, S.P., Permeability of cracked hybrid fiber$580 \quad$ reinforced mortar under load. Materials Journal, 2002. 99(4): 379-385.

58117 Lawler, J. S., Zampini, D. and Shah, S.P., Microfiber and macrofiber hybrid fiber582 reinforced concrete. Journal of Materials in Civil Engineering, 2005. 17(5): 595-604. MRS Proceedings. 1990. Cambridge Univ Press.

19 Larsen, E.S. and Krenchel, H., Durability of FRC-materials. in MRS Proceedings. 1990. Cambridge Univ Press.

20 Banthia, N. and Soleimani, S.M., Flexural response of hybrid fiber-reinforced cementitious composites. ACI Materials Journal, 2005. 102(6): 382.

58921 Feldman, D. and Zheng, Z., Synthetic fibres for fibre concrete composites. in MRS $590 \quad$ Proceedings. 1993. Cambridge Univ Press.

59122 Banthia, N. and Sappakittipakorn, M., Toughness enhancement in steel fiber reinforced 592 concrete through fiber hybridization. Cement and Concrete Research, 2007. 37(9): 1366-1372. 
23 Yao, W., Li, J. and Wu, K., Mechanical properties of hybrid fibre-reinforced concrete at low fibre volume fraction. Cement and concrete research, 2003. 33(1): 27-30.

24 Kang, S.-T., Choi, J.-Il, Koh, K.-T., Lee, K. S. and Lee, B. Y., Hybrid effects of steel fiber and microfiber on the tensile behaviour of ultra-high performance concrete. Composite Structures, 2016. 145: 37-42.

25 Park, S.H., Kim, D.J., Ryu, G.S. and Koh, K.T., Tensile behaviour of ultra-high performance hybrid fiber reinforced concrete. Cement and Concrete Composites, 2012. 34(2): 172-184.

26 Yu, R., Spiesz, P. and Brouwers, H.J.H., Static properties and impact resistance of a green Ultra-High Performance Hybrid Fibre Reinforced Concrete (UHPHFRC): experiments and modelling. Construction and Building Materials, 2014. 68: 158-171.

27 ACI Committee, American Concrete Institute. Building code requirements for structural concrete (ACI 318M-14) and commentary, 2014. American Concrete Institute.

28 Razvi, S.R. and Saatcioglu, M., Strength and deformability of confined high-strength concrete columns. ACI Structural Journal, 1994. 91(6): 678-687.

29 Pessiki, S. and Pieroni, A., Axial load behaviour of large-scale spirally-reinforced highstrength concrete columns. ACI Structural journal, 1997. 94(3): 304-314.

30 GanZhou Daye Metalic Fibres Company Ltd. 2016 [cited 201603 June]; Available from: http://www.gzdymf.com/index_en.html.

31 Fibercon Australia, 2016 [cited $2016 \quad 15$ July]; Available from: http://www.fibercon.com.au/.

32 Hadi, M.N.S., Pham, T.M. and Lei, X., New method of strengthening reinforced concrete square columns by circularizing and wrapping with fiber-reinforced polymer or steel straps. Journal of Composites for Construction, 2012. 17(2): 229-238. 
33 Hadi, M.N.S., Behaviour of eccentric loading of FRP confined fibre steel reinforced concrete columns. Construction and Building Materials, 2009. 23(2): 1102-1108.

34 Hadi, M.N.S. and Widiarsa, I.B.R., Axial and flexural performance of square RC columns wrapped with CFRP under eccentric loading. Journal of Composites for Construction, 2012. 16(6): 640-649.

35 Saljoughian, A. and Mostofinejad, D., Corner Strip-Batten Technique for FRPConfinement of Square RC Columns under Eccentric Loading. Journal of Composites for Construction, 2015. 20(3): 04015077.

36 ASTM Subcommittee D20. 10 on Mechanical Properties, Standard test Methods for Flexural Properties of Unreinforced and Reinforced Plastics and Electrical Insulating Materials. American Society for Testing Materials, 1997.

37 Hadi, M.N.S., Khan, Q.S. and Sheikh, M.N., Axial and flexural behavior of unreinforced and FRP bar reinforced circular concrete filled FRP tube columns. Construction and Building Materials, 2016. 122: 43-53.

38 Markovic, I., High-performance hybrid-fibre concrete-development and utilisation. Technische Universität Delft. 2006, Ph. D. thesis.

39 Banthia, N. and Trottier, J.F., Concrete Reinforced with Deformed Steel Fibers--Part II: Toughness Characterization. ACI Materials Journal-American Concrete Institute, 1995. 92(2): 146-154.

40 Hadi, M.N., Behaviour of eccentric loading of FRP confined fibre steel reinforced concrete columns. Construction and Building Materials, 2009. 23(2): 1102-1108.

41 Hosinieh, M. M., Aoude, H., Cook, W. D., Mitchell, D., Behavior of ultra-high performance fiber reinforced concrete columns under pure axial loading, Engineering Structures, 99 (2015) 388-401. 
64242 Banthia, N. and Trottier, J.F., Concrete reinforced with deformed steel fibers, part I: bond-slip mechanisms. ACI Materials Journal-American Concrete Institute, 1994.

644 91(5): 435-446.

645

646

647

648

649

650

651

652

653

654

655

656

657

658

659

660

661

662

663

664

665

666 
667 List of Tables

668 Table 1: Steel reinforcement details.

669 Table 2: Steel fibres properties.

670 Table 3: Experimental results of specimens tested under concentric loading.

671 Table 4: Experimental results of specimens tested under eccentric loading.

672 Table 5: Experimental results of specimens tested under four-point bending.

673 Table 6: The maximum load and the corresponding moment of the tested specimens.

674

675

676

677

678

679

680

681

682

683

684

685

686

687

688

689

690

691 
692

693

694

695

696

697

698

699

700

701

702

703

704

705

706

707

708

709

710

711

712

713

714

715

716

\section{List of Figures}

Fig. 1: The utilized steel fibres: (a) Deformed steel fibre; (b) Micro steel fibre (MF).

Fig. 2: Specimens dimensions and reinforcement details.

Fig. 3: The fabrication of the tested specimens: (a) Constructing Steel reinforcement cage;

(b) Vertical spacer; (c) Preparing specimens' formwork; (d) Specimens after being cast.

Fig. 4: Testing equipment: (a) The compression testing machine supplied with LVDTs during concentric loading test (HF-E0); (b) Loading head equipment; (c) Loading head details.

Fig. 5: Specimen DF-PB under four-point bending test.

Fig. 6: Buckling of the longitudinal steel bar and rupture of the confining helix of NF-E0.

Fig. 7: Mode of failure of specimens tested under concentric and (25 mm and $50 \mathrm{~mm})$ eccentric axial load.

Fig. 8: Mode of failure of specimens tested under four-point bending.

Fig. 9: The elongation of the longitudinal steel bar in the tension zone of NF-E0 Specimen.

Fig. 10: Ductility calculation of the tested specimens.

Fig. 11: The axial load- axial deformation curves of the RPC specimens concentrically loaded.

Fig. 12: The axial load-axial deformation of the RPC specimens eccentrically loaded: (a) at 25 $\mathrm{mm}$; (b) at $50 \mathrm{~mm}$.

Fig. 13: The bending load-midspan deflection of the RPC specimens tested under four-point bending.

Fig. 14: The experimental axial load-bending moment interaction diagram of the tested specimens under concentric loading, eccentric loading $(25 \mathrm{~mm}$ and $50 \mathrm{~mm})$ and four-point bending. 
Table 1: Steel reinforcement details.

\begin{tabular}{|c|c|c|c|c|c|}
\hline \multirow[t]{2}{*}{ Group } & \multirow[t]{2}{*}{ Specimen } & \multirow{2}{*}{$\begin{array}{l}\text { Longitudinal } \\
\text { Reinforcement }\end{array}$} & \multirow{2}{*}{$\begin{array}{l}\text { Transverse } \\
\text { Reinforcement }\end{array}$} & \multirow{2}{*}{$\begin{array}{l}\text { Steel fibre type } \\
\text { and content }\end{array}$} & \multirow{2}{*}{$\begin{array}{l}\text { Loading } \\
\text { conditions }\end{array}$} \\
\hline & & & & & \\
\hline & NF-E0 & & & & Concentric \\
\hline \multirow[t]{4}{*}{$\mathrm{NF}$} & NF-E25 & $6 \mathrm{~N} 12$ & R10@40 mm & - & $25 \mathrm{~mm}$ Eccentric \\
\hline & NF-E50 & & & & $50 \mathrm{~mm}$ Eccentric \\
\hline & NF-PB & & & & four-point bending \\
\hline & MF-E0 & & & & Concentric \\
\hline \multirow[t]{4}{*}{ MF } & MF-E25 & $6 \mathrm{~N} 12$ & R10@40 mm & $4 \% \mathrm{MF}$ & $25 \mathrm{~mm}$ Eccentric \\
\hline & MF-E50 & & & & $50 \mathrm{~mm}$ Eccentric \\
\hline & MF-PB & & & & four-point bending \\
\hline & DF-E0 & & & & Concentric \\
\hline \multirow[t]{4}{*}{ DF } & DF-E25 & $6 \mathrm{~N} 12$ & R10@40 mm & $2 \% \mathrm{DF}$ & $25 \mathrm{~mm}$ Eccentric \\
\hline & DF-E50 & & & & $50 \mathrm{~mm}$ Eccentric \\
\hline & DF-PB & & & & four-point bending \\
\hline & HF-E0 & & & & Concentric \\
\hline \multirow[t]{3}{*}{$\mathrm{HF}$} & HF-E25 & $6 \mathrm{~N} 12$ & R10@40 mm & $2 \% \mathrm{MF}$ and $1 \% \mathrm{DF}$ & $25 \mathrm{~mm}$ Eccentric \\
\hline & HF-E50 & & & & $50 \mathrm{~mm}$ Eccentric \\
\hline & HF-PB & & & & four-point bending \\
\hline
\end{tabular}


Table 2: Steel fibres properties of MF [30] and DF [31].

\begin{tabular}{lcccc}
\hline Steel fibre & Label & Length & Diameter & Nominal tensile strength \\
& & $(\mathrm{mm})$ & $(\mathrm{mm})$ & 2900 \\
\hline Micro steel fibre & MF & 6 & 0.2 & 800 \\
Deformed steel fibre & DF & 18 & 0.55 & \\
\hline
\end{tabular}

732

733

734

735

736

737

738

739

740

741

742

743

744

745

746 
Table 3: Experimental results of specimens tested under concentric loading.

\begin{tabular}{lcccc}
\hline Specimen & NF-E0 & MF-E0 & DF-E0 & HF-E0 \\
\hline Yield load (kN) & 3168 & 4279 & 3486 & 3834 \\
Axial deformation at yield load (mm) & 4.4 & 5.5 & 4.7 & 4.8 \\
Maximum load (kN) & 3304 & 4373 & 3607 & 4055 \\
Axial deformation at Maximum load (mm) & 4.6 & 5.7 & 4.9 & 5.1 \\
Axial deformation at 85\% post maximum load (mm) & 4.7 & 6.4 & 5.1 & 7.2 \\
Ductility & 1.1 & 1.3 & 1.2 & 2.0 \\
\hline
\end{tabular}

752

753

754

755

756

757

758

759

760

761

762

763

764

765 
Table 4: Experimental results of specimens tested under eccentric loading.

\begin{tabular}{|c|c|c|c|c|c|c|c|c|}
\hline \multirow[b]{2}{*}{ Specimen } & \multicolumn{4}{|c|}{$25 \mathrm{~mm}$ eccentricity } & \multicolumn{4}{|c|}{$50 \mathrm{~mm}$ eccentricity } \\
\hline & NF-E25 & MF-E25 & DF-E25 & HF-E25 & NF-E50 & MF-E50 & DF-E50 & HF-E50 \\
\hline Yield load $(\mathrm{kN})$ & 2111 & 2763 & 2178 & 2330 & 1285 & 1626 & 1368 & 1463 \\
\hline $\begin{array}{l}\text { Axial deformation at } \\
\text { yield load (mm) }\end{array}$ & 3.7 & 4.5 & 3.9 & 4.2 & 5.8 & 7.3 & 6.2 & 7.3 \\
\hline Maximum load (kN) & 2194 & 2835 & 2246 & 2511 & 1327 & 1711 & 1414 & 1528 \\
\hline $\begin{array}{l}\text { Axial deformation at } \\
\text { maximum load (mm) }\end{array}$ & 3.9 & 4.7 & 4.0 & 4.7 & 6.0 & 7.8 & 6.5 & 7.8 \\
\hline Lateral deformation (mm) & 2.1 & 2.8 & 2.7 & 2.8 & 3.7 & 4.2 & 3.9 & 4.2 \\
\hline $\begin{array}{l}\text { Axial deformation at } 85 \% \\
\text { post maximum load (mm) }\end{array}$ & 3.9 & 5.3 & 4.0 & 5.1 & 6.0 & 9.2 & 6.5 & 9.5 \\
\hline Ductility & 1.1 & 1.3 & 1.1 & 1.4 & 1.1 & 1.5 & 1.1 & 1.6 \\
\hline
\end{tabular}

771

772

773

774

775

776

777

778

779

780 
Table 5: Experimental results of specimens tested under four-point bending.

\begin{tabular}{lcccc}
\hline Specimen & NF-PB & MF-PB & DF-PB & HF-PB \\
\hline Yield load (kN) & 307 & 351 & 345 & 360 \\
Midspan deflection at yield load (mm) & 4.3 & 5.2 & 5.4 & 5.1 \\
Maximum load (kN) & 356 & 393 & 379 & 389 \\
Midspan deflection at maximum load (mm) & 6.5 & 7.8 & 7.6 & 7.7 \\
Midspan deflection at 85\% post maximum load (mm) & 6.6 & 26.3 & 23.2 & 32.7 \\
Ductility & 2.0 & 8.3 & 7.0 & 10.3 \\
\hline
\end{tabular}

787 
Table 6: The maximum load and the corresponding moment of the tested specimens.

\begin{tabular}{|c|c|c|c|c|}
\hline Specimen & Maximum load & Lateral deformation at $\mathrm{P}_{\max }$ & Midspan deflection at $\mathrm{P}_{\max }$ & Moment Capacity \\
\hline & $\mathrm{P}_{\max }(\mathrm{kN})$ & $\delta_{\text {lateral }}(\mathrm{mm})$ & $\Delta_{\text {midspan }}(\mathrm{mm})$ & $\mathrm{M}_{\max }(\mathrm{kN} \cdot \mathrm{m})$ \\
\hline NF-E0 & 3304 & - & - & 0 \\
\hline NF-E25 & 2194 & 2.1 & - & 59 \\
\hline NF-E50 & 1327 & 3.7 & - & 71 \\
\hline NF-PB & 356 & - & 6.5 & 41 \\
\hline MF-E0 & 4373 & - & - & 0 \\
\hline MF-E25 & 2835 & 2.8 & - & 78 \\
\hline MF-E50 & 1711 & 4.3 & - & 92 \\
\hline MF-PB & 393 & - & 7.8 & 44 \\
\hline DF-E0 & 3607 & - & - & 0 \\
\hline DF-E25 & 2246 & 2.7 & - & 62 \\
\hline DF-E50 & 1414 & 3.8 & - & 76 \\
\hline DF-PB & 379 & - & 7.6 & 44 \\
\hline HF-E0 & 4055 & - & - & 0 \\
\hline HF-E25 & 2511 & 2.8 & - & 69 \\
\hline HF-E50 & 1528 & 4.1 & - & 82 \\
\hline HF-PB & 389 & - & 7.7 & 45 \\
\hline
\end{tabular}

805 

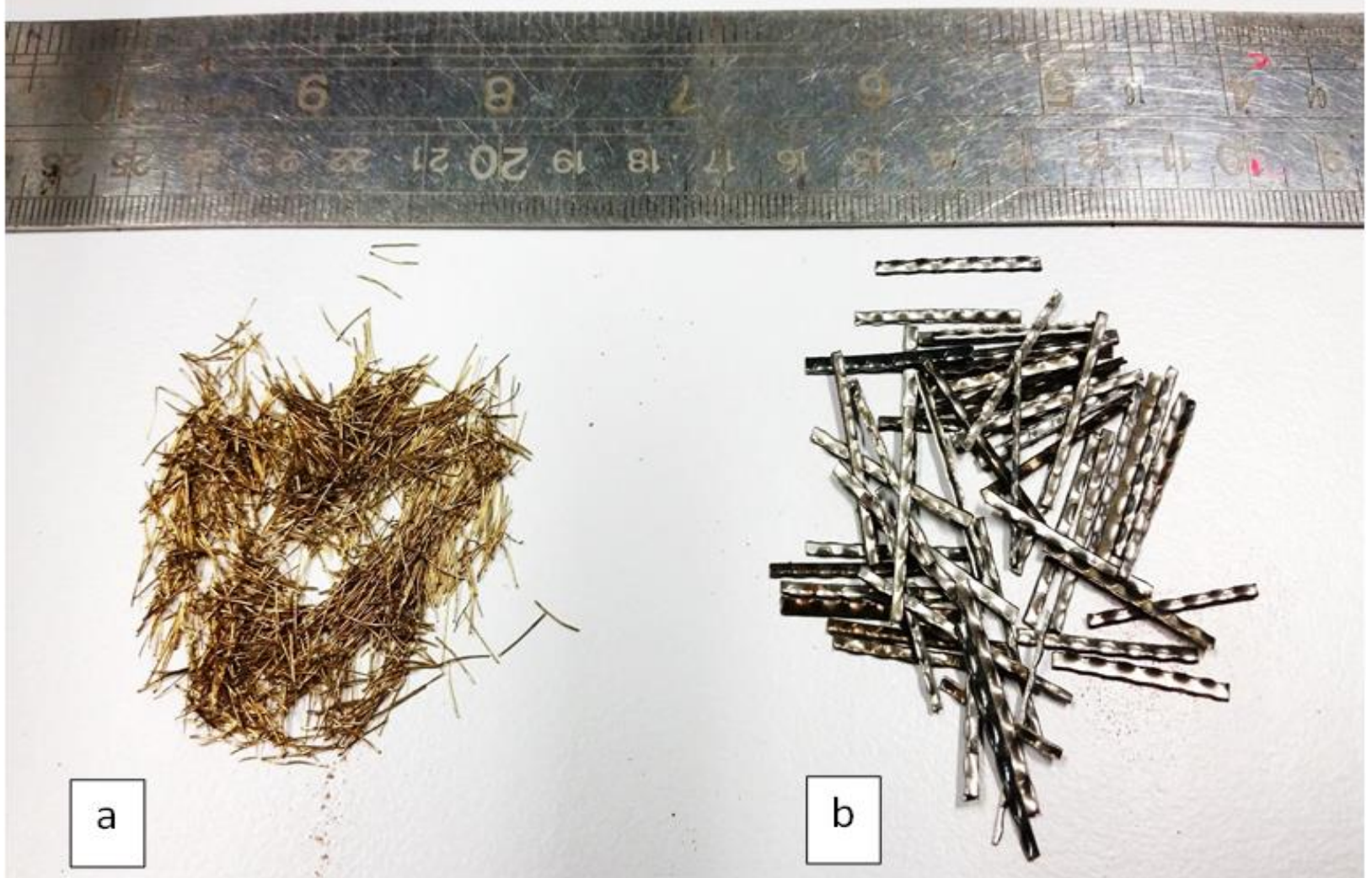

815

816

Fig. 1: The utilized steel fibres: (a) Micro steel fibre (MF); (b) Deformed steel fibre (DF).

817

818

819

820

821

822 


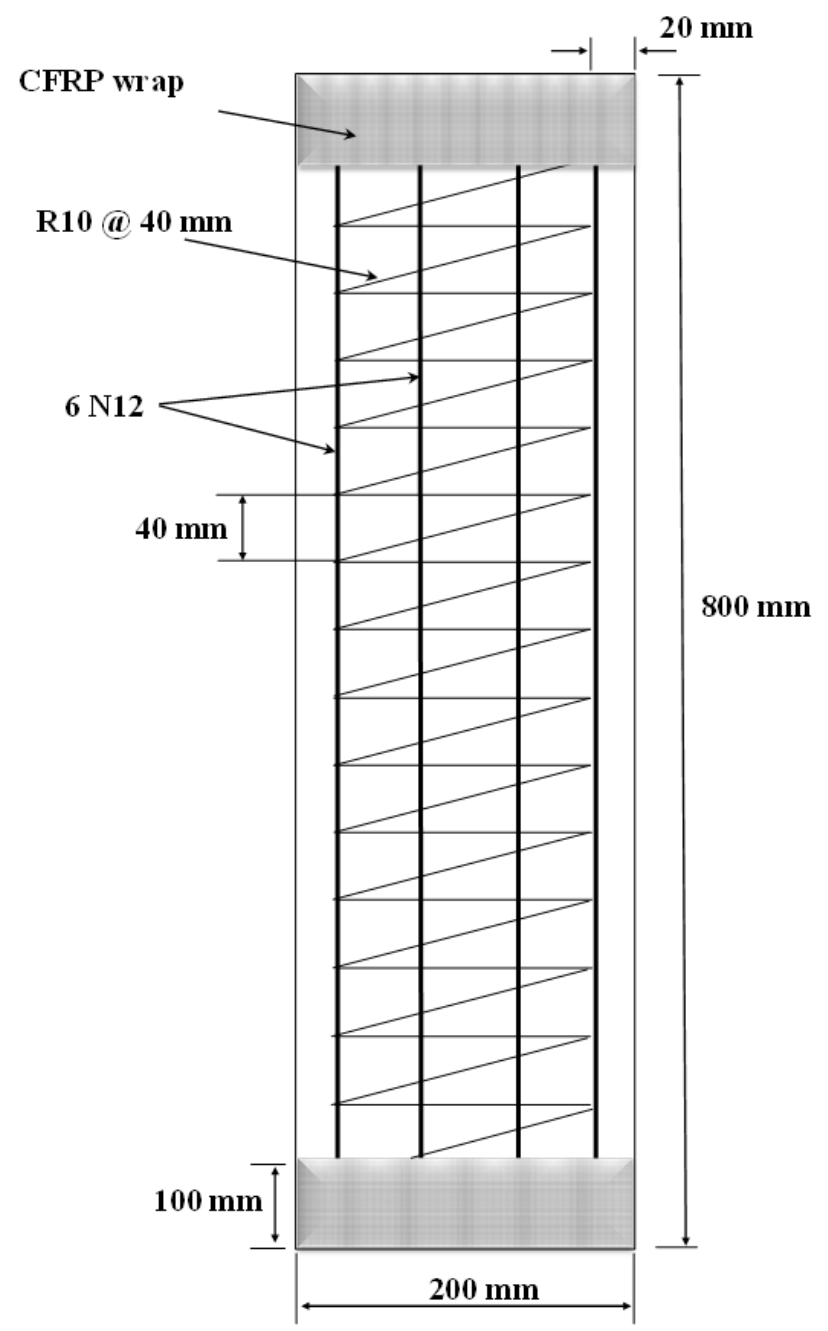

Fig. 2: Dimensions of Specimens and reinforcement details. 

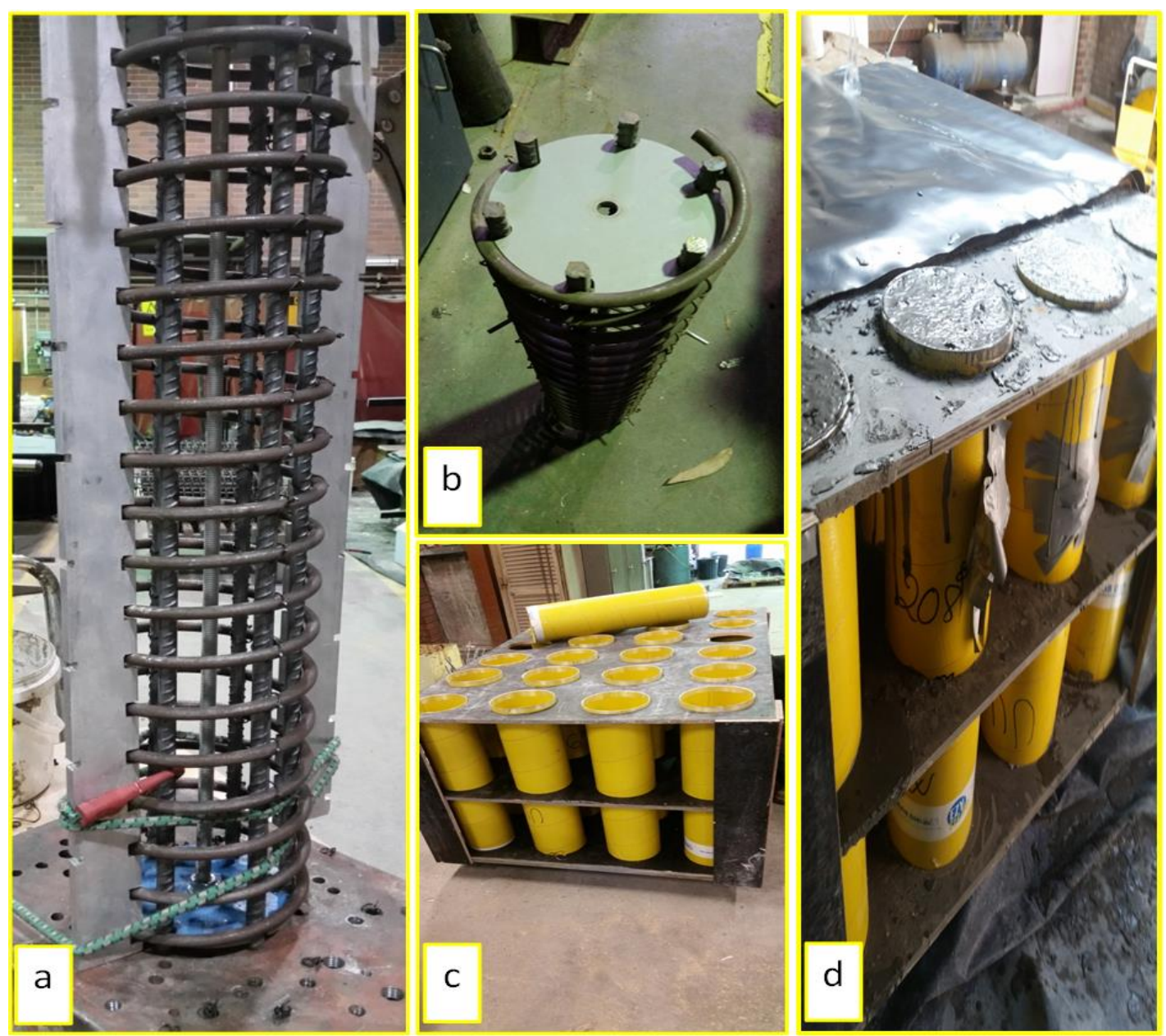

Fig. 3: The fabrication of the tested specimens: (a) Constructing steel reinforcement cage; (b) Horizontal spacer; (c) Preparing specimens' formwork; (d) Specimens after being cast. 


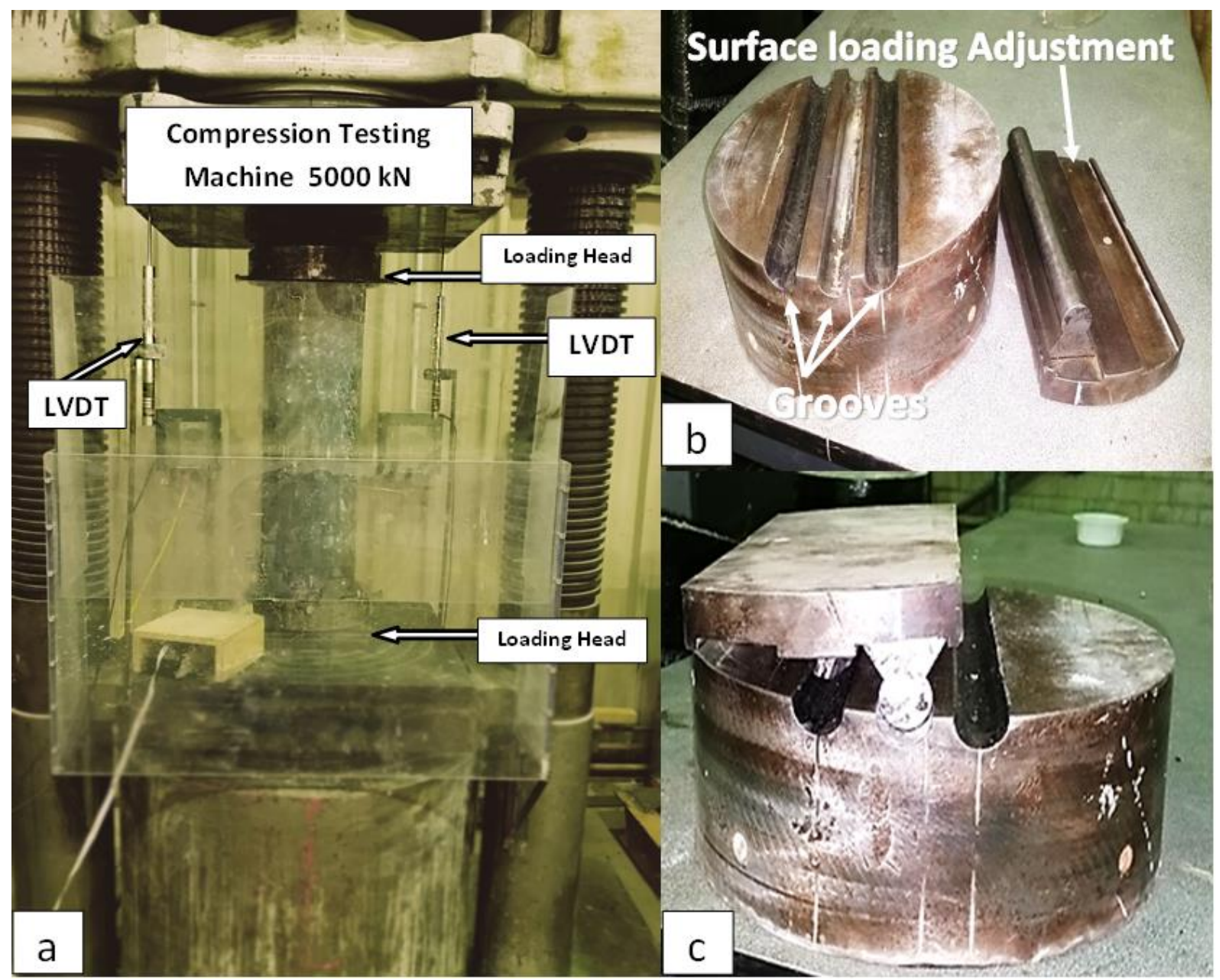

849 Fig. 4: Testing equipment: (a) The compression testing machine supplied with LVDTs during 


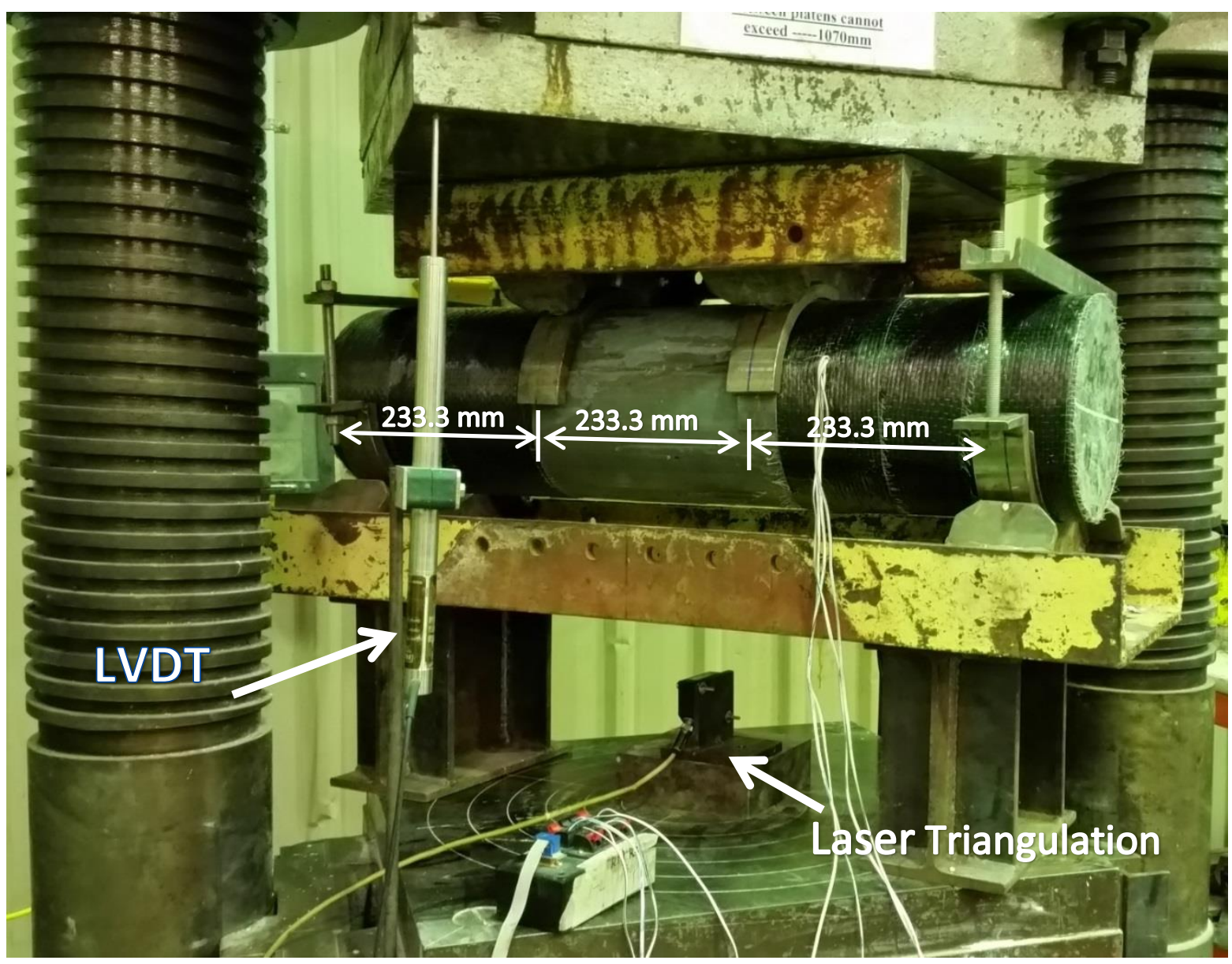

862 


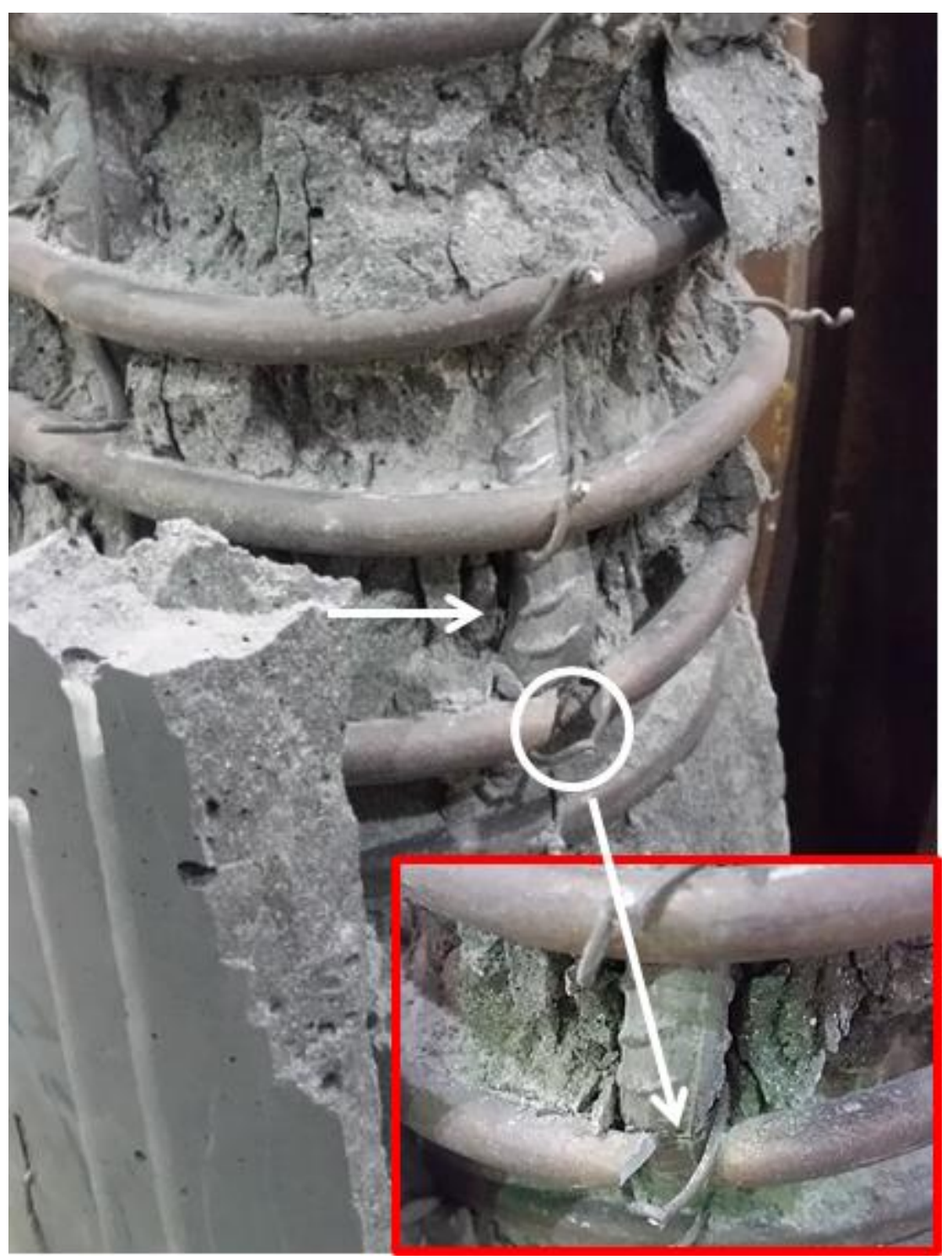

876 Fig. 6: Buckling of the longitudinal steel bar and rupture of the confining helix of Specimen 


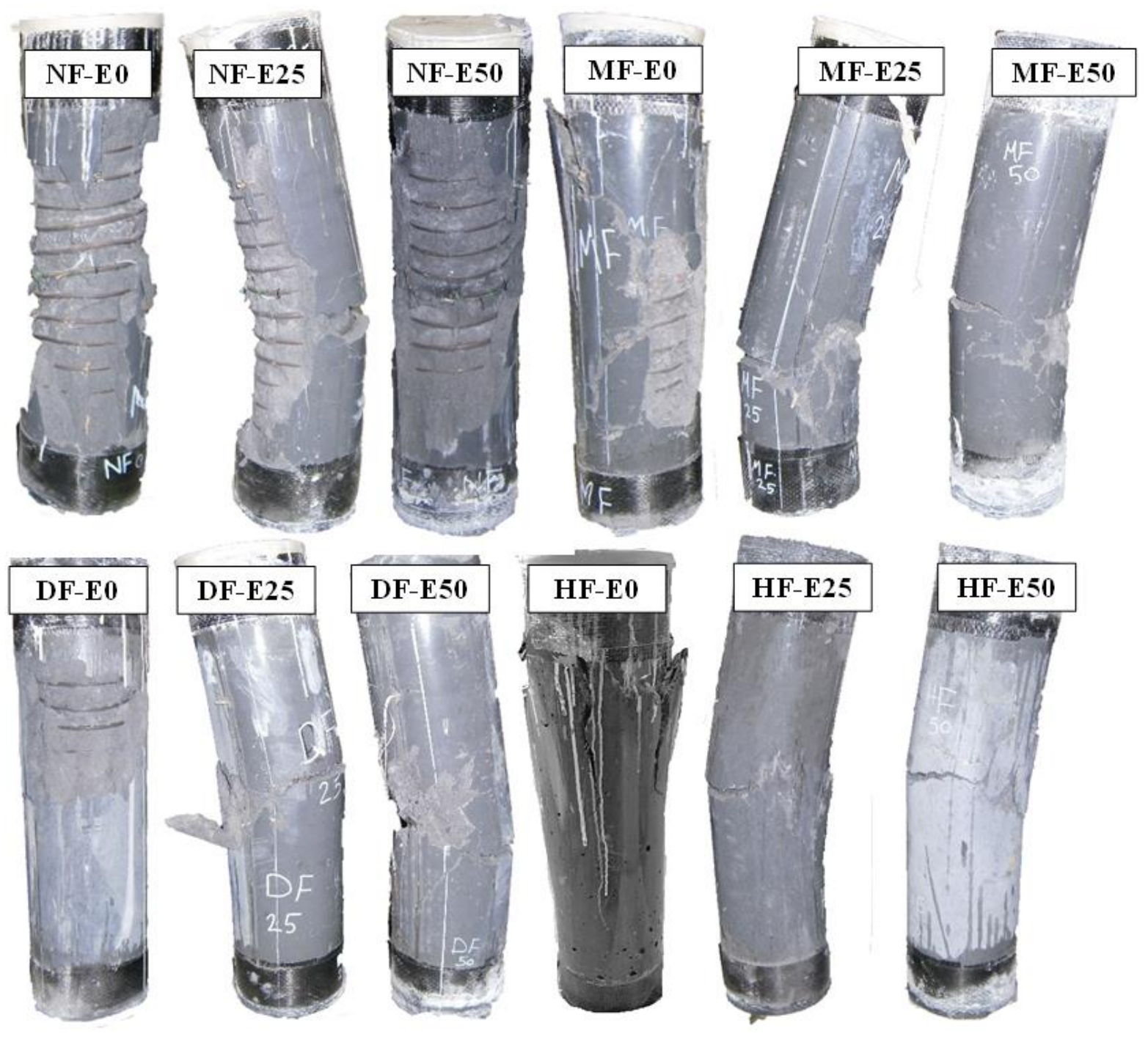

Fig. 7: Mode of failure of specimens tested under concentric and $25 \mathrm{~mm}$ and $50 \mathrm{~mm}$ eccentric axial load. 


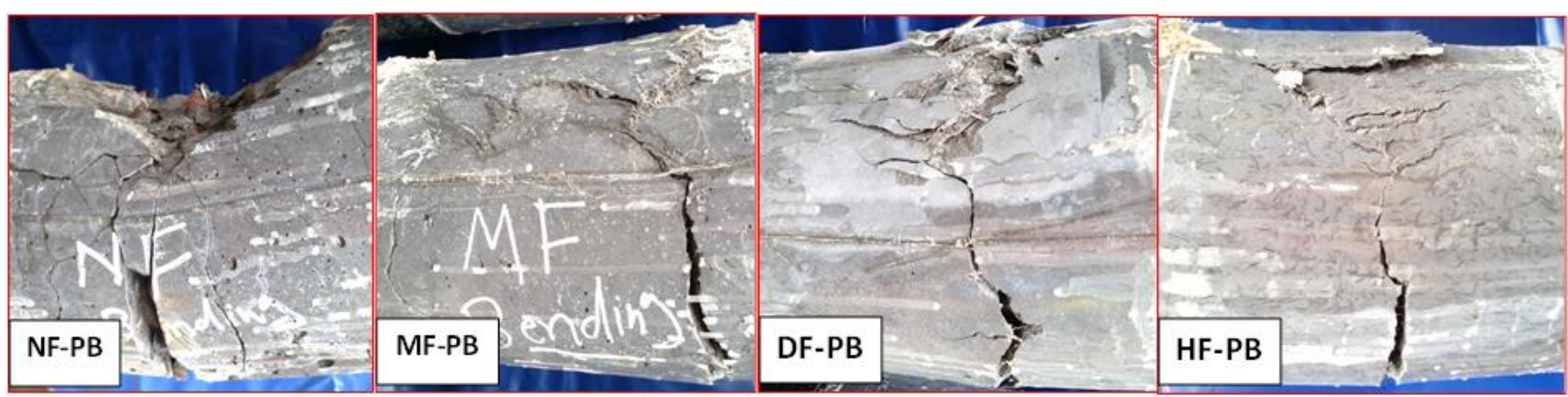

Fig. 8: Close view of the mode of failure of specimens tested under four-point bending. 


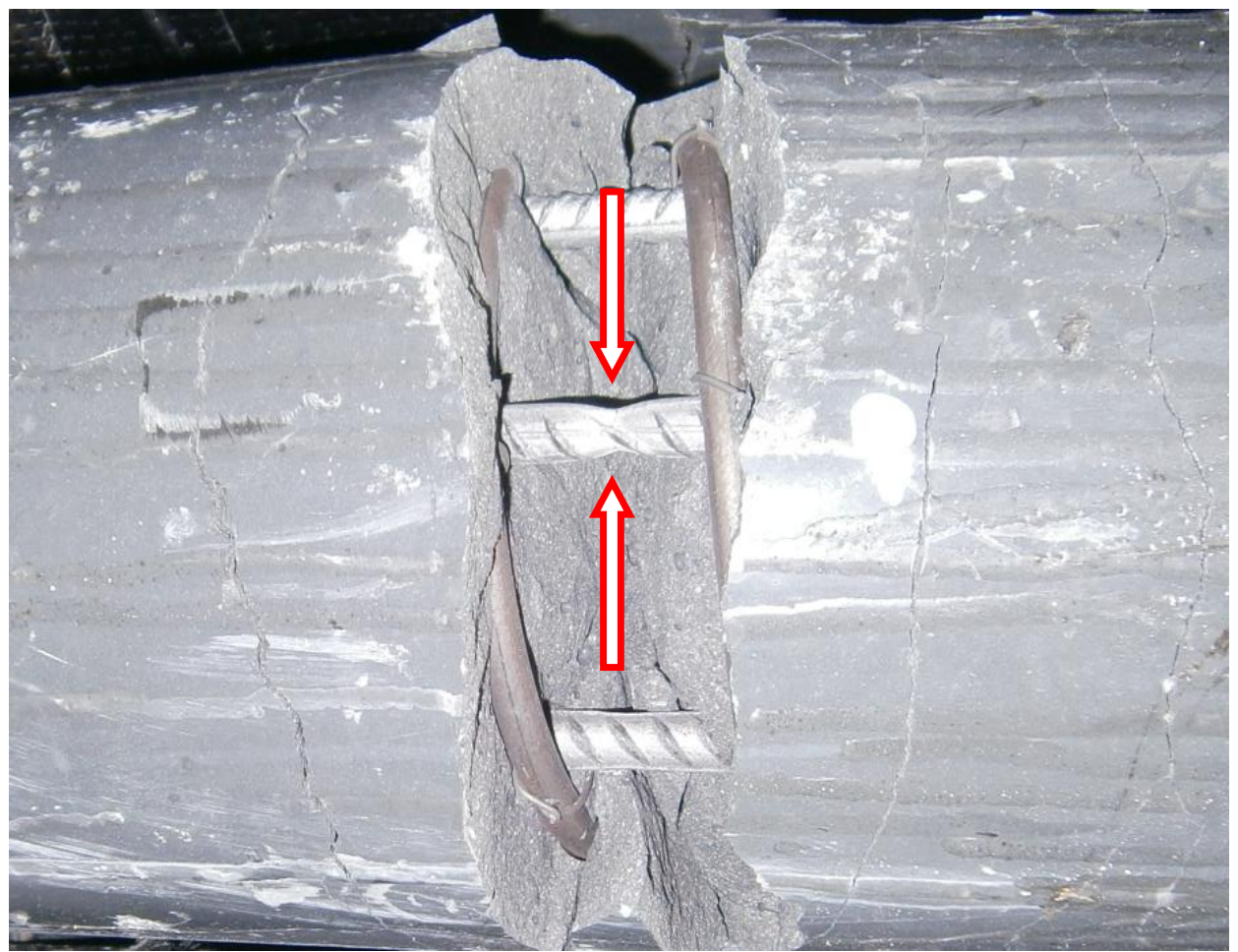

Fig. 9: Specimen NF-PB tested under four-point bending.

907

908

909

910

911

912

913 


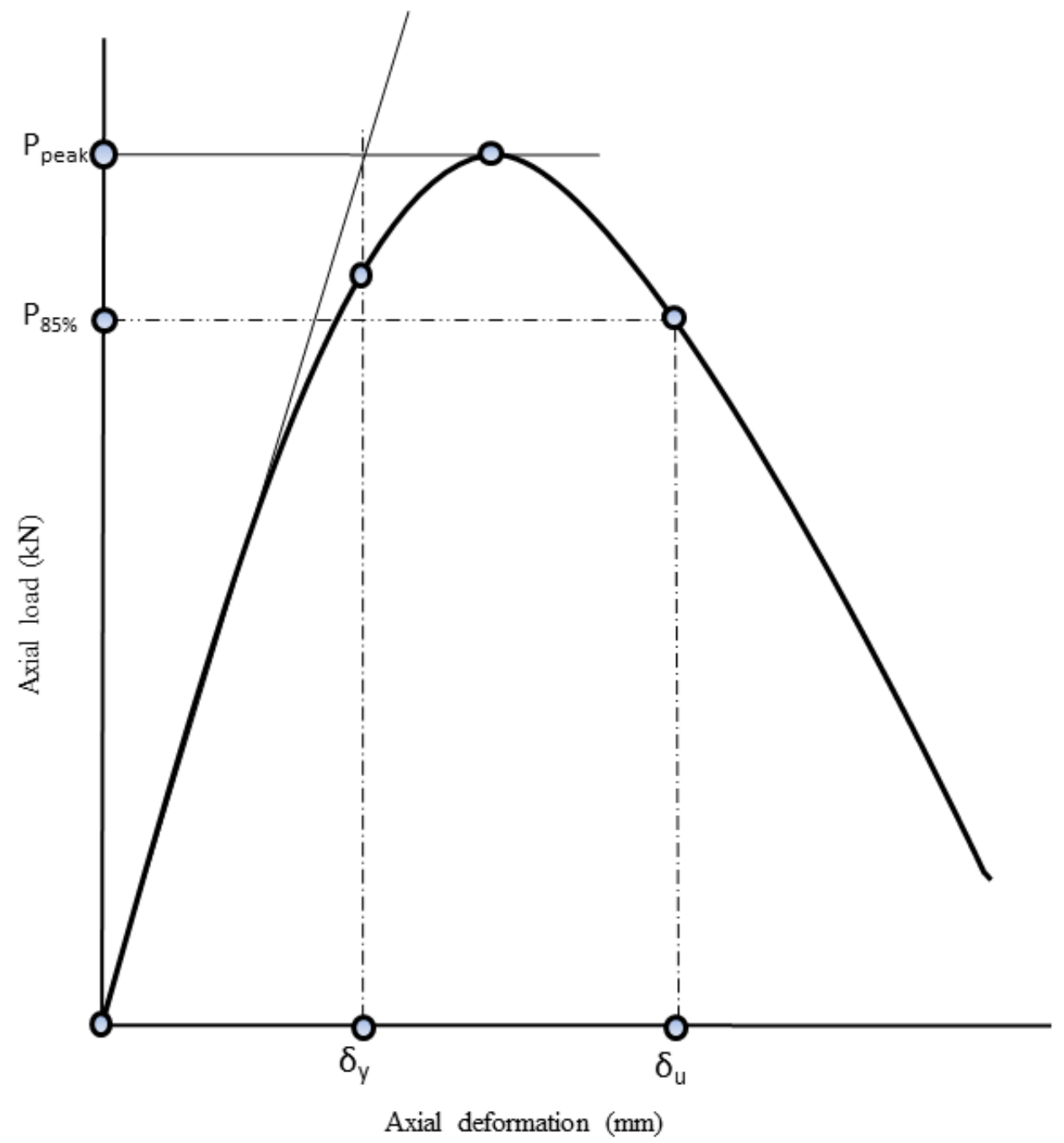




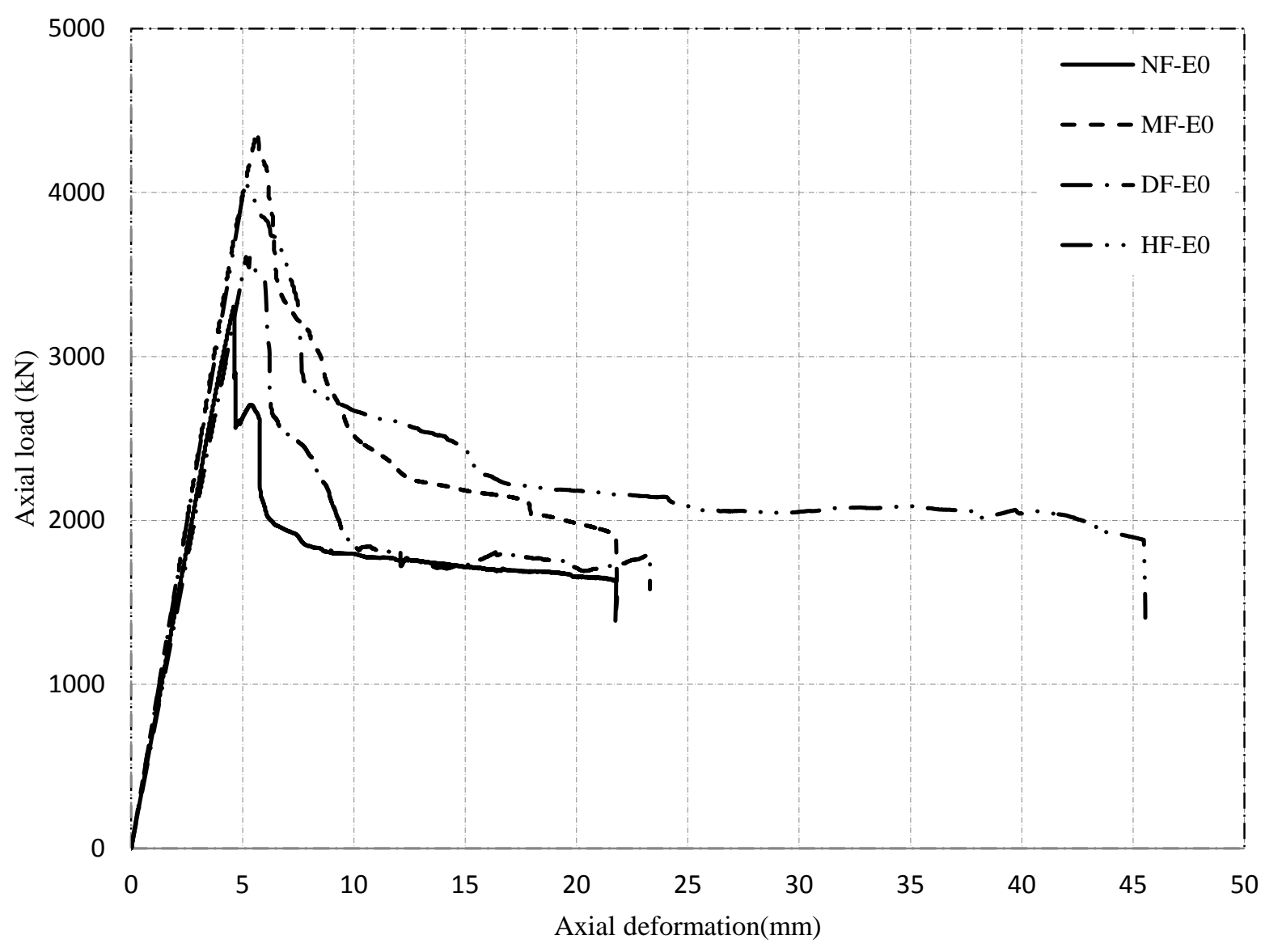

928

929 930 931 932 933 934 935 936 937 


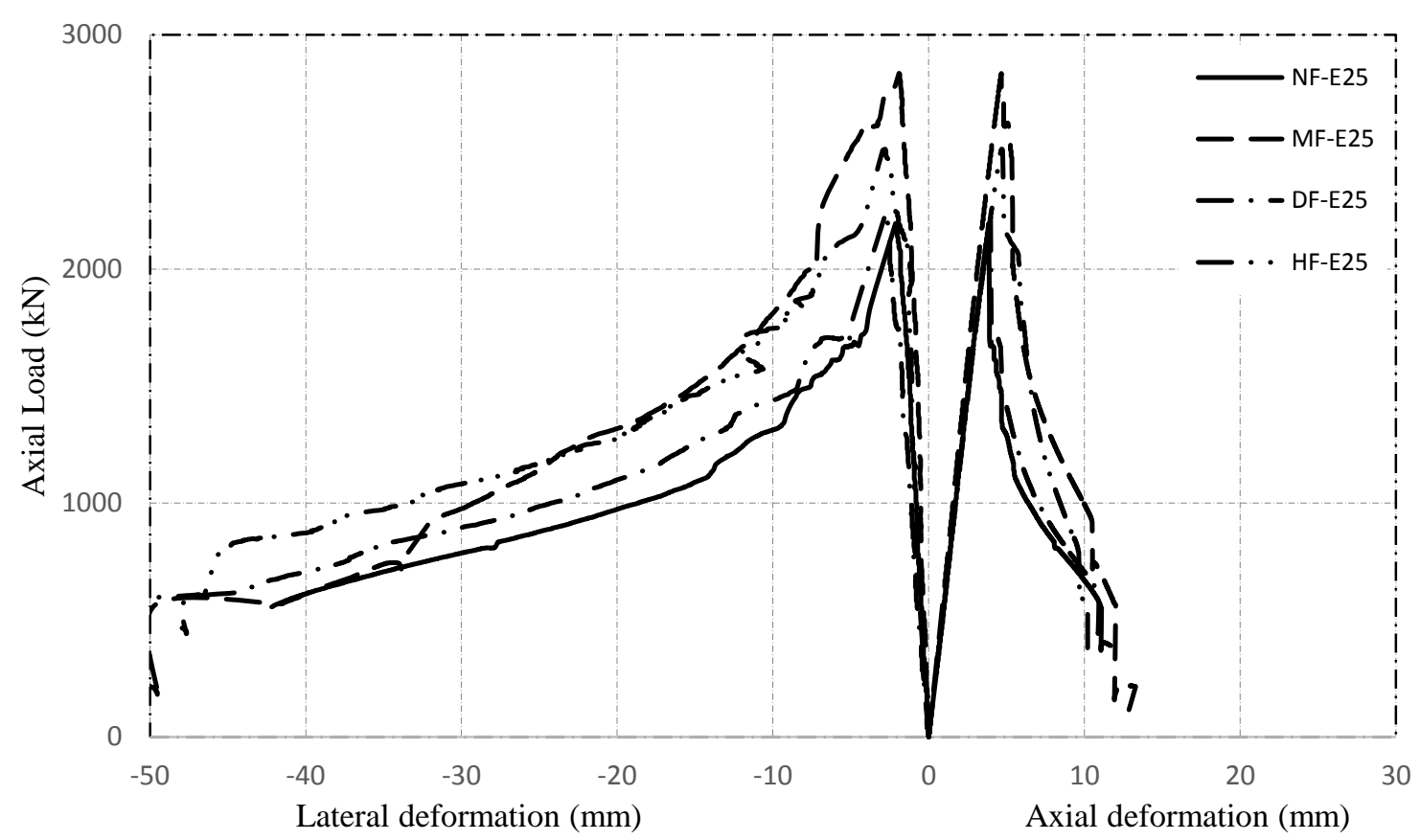

941

(a)

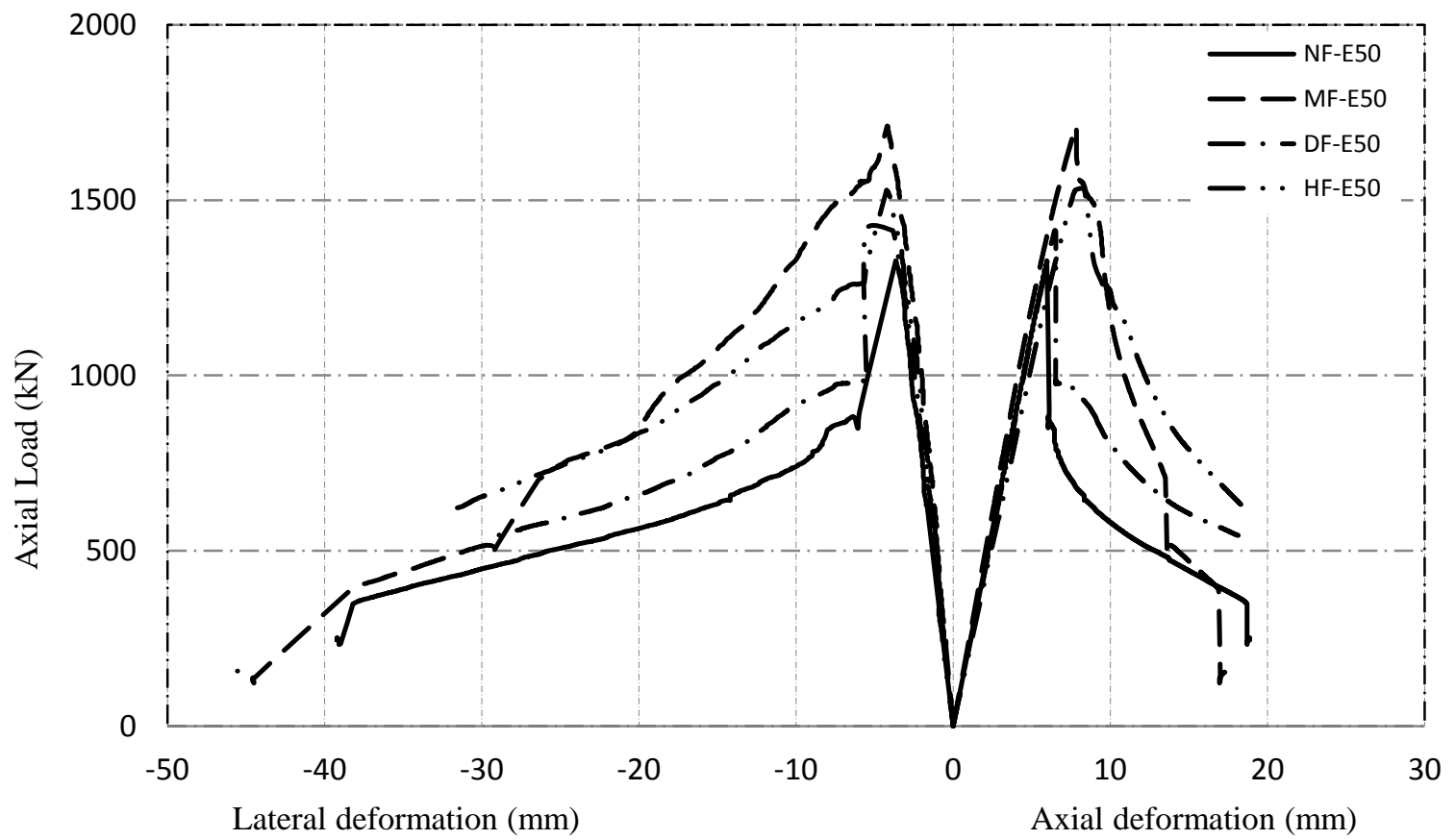

(b)

Fig. 12: The axial load-axial deformation of the RPC specimens eccentrically loaded: (a) at 25 $\mathrm{mm}$; (b) at $50 \mathrm{~mm}$. 


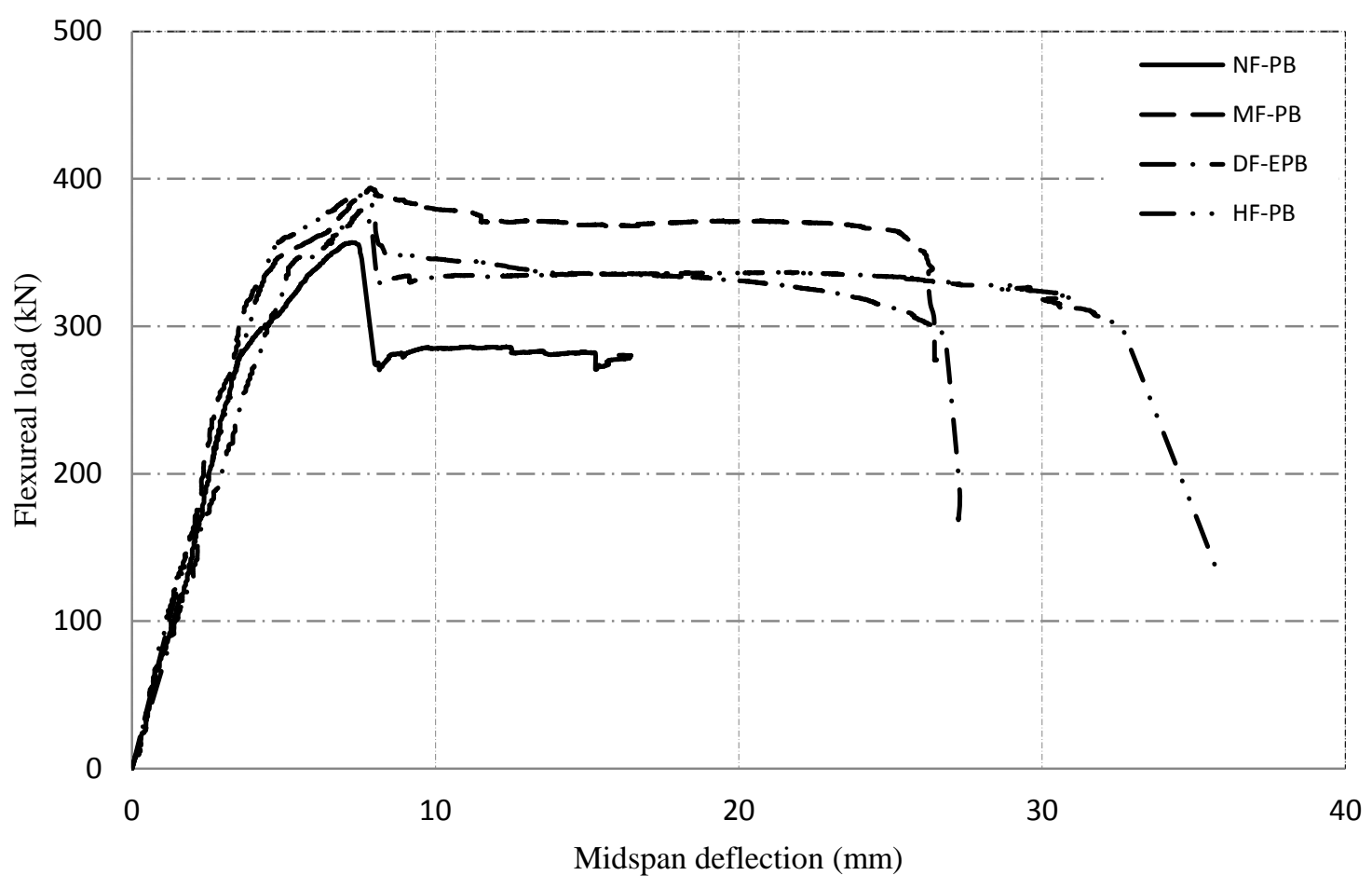

Fig. 13: The flexural load-midspan deflection of the RPC specimens tested under four-point bending. 


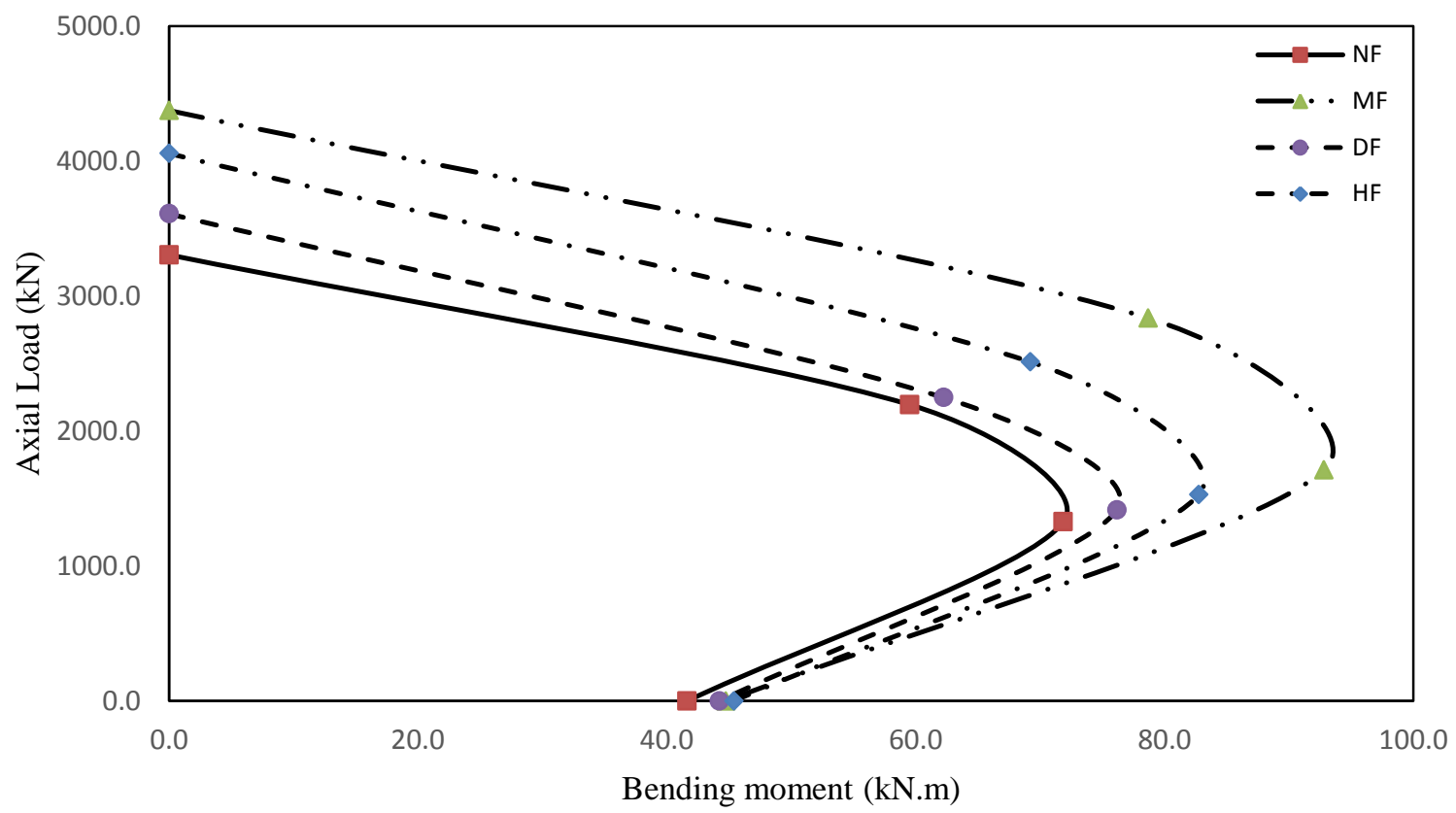

Fig. 14: The experimental axial load-bending moment interaction diagrams of the tested specimens. 